NBER WORKING PAPER SERIES

\title{
QUANTIFYING BRAND LOYALTY: EVIDENCE FROM THE CIGARETTE MARKET
}

\author{
Philip DeCicca \\ Donald S. Kenkel \\ Feng Liu \\ Jason Somerville \\ Working Paper 28690 \\ http://www.nber.org/papers/w28690
NATIONAL BUREAU OF ECONOMIC RESEARCH
1050 Massachusetts Avenue
Cambridge, MA 02138
April 2021

We thank David Wasser for excellent research assistance. We thank Kitt Carpenter, Resul Cesur, Paul Contoyannis, Mike Darden, Andrew Goodman-Bacon, Jerry Hurley, Steve Ross, Mike Veall, Casey Warman, seminar participants at the University of Connecticut, Dalhousie University, McMaster University, University of Tennessee and Vanderbilt University, and two anonymous referees for helpful comments. The opinions expressed herein are those of the authors and not necessarily those of the Federal Reserve Bank of New York or the Federal Reserve System. Researchers' own analyses calculated (or derived) based in part on data from The Nielsen Company (US), LLC and marketing databases provided through the NielsenIQ Datasets at the Kilts Center for Marketing Data Center at The University of Chicago Booth School of Business. The conclusions drawn from the NielsenIQ data are those of the researcher(s) and do not reflect the views of NielsenIQ. NielsenIQ is not responsible for, had no role in, and was not involved in analyzing and preparing the results reported herein. Kenkel acknowledges partial support from the National Institutes of Health, Grant Number 5R01DA042064-03. The views expressed herein are those of the authors and do not necessarily reflect the views of the National Bureau of Economic Research.

NBER working papers are circulated for discussion and comment purposes. They have not been peerreviewed or been subject to the review by the NBER Board of Directors that accompanies official NBER publications.

(C) 2021 by Philip DeCicca, Donald S. Kenkel, Feng Liu, and Jason Somerville. All rights reserved. Short sections of text, not to exceed two paragraphs, may be quoted without explicit permission provided that full credit, including $\odot$ notice, is given to the source. 
Quantifying Brand Loyalty: Evidence from the Cigarette Market

Philip DeCicca, Donald S. Kenkel, Feng Liu, and Jason Somerville

NBER Working Paper No. 28690

April 2021

JEL No. I12

\title{
ABSTRACT
}

We exploit a quasi-experiment created when New York State began in 2011 to tax cigarettes sold on Native American Reservations. The regime change represents a unique opportunity to quantify brand loyalty because it almost doubled the price of premium-brand cigarettes, while Native brands were still untaxed. We use data from two different sources- the New York State Adult Tobacco Survey and the Nielsen Homescan Panel. We find that the increase in relative prices led to substantial declines in premium cigarette purchases. However, even among the premium consumers with the most to gain from switching, about three-quarters remained brand loyal.

\author{
Philip DeCicca \\ Feng Liu \\ Ball State University \\ School of Management and Economics \\ 117 Whitninger Building \\ Chinese University of Hong Kong, Shenzhen \\ Muncie, IN 47303 \\ fliu22@gmail.com \\ and NBER \\ ppdecicca@bsu.edu \\ Jason Somerville \\ 33 Liberty Street \\ Donald S. Kenkel \\ New York, NY 10045 \\ Department of Policy Analysis \\ jasonjsomerville@gmail.com \\ and Management \\ College of Human Ecology \\ Cornell University \\ Martha Van Rensselaer Hall \\ Ithaca, NY 14853-4401 \\ and NBER \\ dsk10@cornell.edu
}

A data appendix is available at http://www.nber.org/data-appendix/w28690 


\section{Introduction and Background}

In many markets, consumers show preferences for specific brands of otherwise similar or even identical products (Bronnenberg, Dubé, and Moorthy 2019). Consumers are willing to pay a substantially higher price for national-brand aspirin, even though store-brand aspirin contains the same active ingredient (Bronnenberg et al. 2015). ${ }^{1}$ Studies have explored consumer brand loyalty for many other goods including breakfast cereals (Shum 2004), orange juice and margarine (Dube, Hitsch and Rossi 2010), automobiles (Anderson et al. 2013) and residential electricity (Hortaçsu, Madanizadeh, and Puller 2017). Studies of brand loyalty often only observe market equilibria - the endogenous pricing and advertising strategies chosen by profitmaximizing firms and the resulting price differentials and market shares. The strength of brand-choice inertia has created a challenge for researchers seeking to quantify brand loyalty; rarely are exogenous price changes of a sufficient magnitude to induce substantial switching by consumers.

We study a quasi-experiment that almost doubled the relative price of premium-brand cigarettes. We quantify brand loyalty and address the empirical question: How many consumers continued to regularly purchase premium brands despite a sharp increase in the price of brand loyalty? The quasi-experiment was created by a change in New York State's (NYS) taxation of cigarettes sold on Indian reservations. ${ }^{2}$ The special legal status of Indian tribes

\footnotetext{
${ }^{1}$ The same study also finds consumer preferences for national-brand salt, sugar, and baking soda, which are essentially identical to the lower-priced store brands.

${ }^{2}$ The U.S. federal government uses the term "Indian" to refer to descendants of the indigenous peoples of the Americas. Another term in common usage is "Native American." We follow most style guides and use the terms as inter-changeable. In data from a 1995 supplement to the Current Population Survey, 50 percent of members of this ethnic/racial group prefer the term Indian, and 37 percent prefer the term Native American (Tucker, Kojetin, and Harrison, 1995).
} 
meant that the NYS cigarette excise tax was not collected on cigarettes sold on reservations until 2011. The tax break was almost fully passed through to lower consumer prices due to intense competition between sellers on most reservations (DeCicca, Kenkel and Liu 2015). By 2010 the tax break was worth $\$ 4.35$ per pack. Untaxed Indian reservation purchases from nonIndian wholesalers accounted for 36 percent of all NYS cigarette sales (Kurti, von Lampe, and Johnson 2015). Starting in June 2011, NYS began to collect the excise tax from the wholesalers of all cigarettes shipped to New York, including those purchased by Indian retailers on reservations. In response, reservation retailers began to only sell Indian-manufactured cigarettes, which remained untaxed by NYS. From 2012-2015, Indian retailer purchases of premium-brand cigarettes from non-Indian wholesalers fell to less than one percent of NYS cigarette sales. ${ }^{3}$

The quasi-experiment in NYS cigarette markets represents a unique opportunity to quantify brand loyalty. Strong brand loyalty has been a long-standing feature of cigarette markets; several studies find annual brand loyalty rates of 85 to 90 percent. ${ }^{4}$ An equally longstanding body of evidence from blind taste tests that most smokers cannot distinguish their preferred brand from other brands. Cigarette brands like Marlboro and Newport sell at a price premium of about $\$ 1.25$ per pack and account for 70 percent of the U.S. market. The success of

\footnotetext{
${ }^{3}$ We thank Marin Kurti for sharing data he obtained through a Freedom of Information request to the NYS Department of Taxation and Finance.

${ }^{4}$ Based on a descriptive analysis of household panel data, Dawes (2014) finds an 86 percent annual retention rate among highly loyal consumers of the three leading cigarette brands. The estimated annual retention rate is consistent with earlier survey evidence that only about 10 percent of smokers switch from their favorite brand in a year (Siegel et al. 1996).
} 
premium brands is commonly attributed to well-known advertising campaigns including the Marlboro Man and Joe Camel. ${ }^{5}$

We use data from the New York State Adult Tobacco Survey (NYS-ATS) and the Nielsen Homescan Panel (NHP) to estimate the treatment effect of the tax-regime change on the demand for premium-brand cigarettes. We allow for heterogeneous treatment effects where the impact of the tax-regime change varies with the consumer's distance to an Indian reservation. We present evidence that both the tax-regime change and the consumer's distance to a reservation are plausibly exogenous and provide credible identification of the heterogeneous treatment effects. In our main specification, we find that for smokers who live very close to an Indian reservation, the regime change reduces the probability of purchasing a premium-brand cigarette by about 18 percentage points in the NYS-ATS and by between 12-15 percentage points in NHP data. The effect of the regime change is spatially heterogeneous and fades with distance, declining to about zero at a distance of about 50-100 miles. To examine what consumers are purchasing instead of premiums, we estimate that the tax-regime change increases the probability of purchasing Indian-manufactured cigarette brands; the effect again varies with distance to a reservation. These estimates mirror the reductions in premium purchases, which suggests switching behavior from premium brands to Native ones. In an

\footnotetext{
${ }^{5}$ Perhaps the most famous cigarette advertising campaign was for Marlboro. The brand was launched in 1927 as a "woman's cigarette" with a filter and was advertised as being "Mild as May" (Brandt 2007). In the 1950s new advertising campaigns re-positioned Marlboro to appeal to the then-much larger market of male smokers. The "Marlboro Man" cowboy is one of the most well-known advertising images in the world. Marlboro became and remains the market-leading brand in the U.S. with about 40 percent market share.
} 
additional specification, we estimate treatment effects that vary by the quintile of the consumer's predicted probability of always purchasing cigarettes from an Indian reservation. We interpret our main results as showing that smokers exhibit a high degree of brand loyalty. First, although we estimate treatment effects that are statistically and economically significant, our results imply that most smokers did not switch away from premium brands despite a sharp increase in price. Prior to the tax-regime change, about 70 percent of consumers in our samples purchased premium cigarettes. Even among the premium consumers with the most to gain from switching, i.e. consumers who lived very near a Native American reservation (NAR) that sold cigarettes, our estimated treatment effects imply that about 73-83 percent of premium smokers who would have remained brand loyal continued to do so. ${ }^{6}$ That is, these premium-brand consumers were willing to pay at least an extra $\$ 4.35$ per pack to remain brand loyal, much more than the price premium of $\$ 1.25$ per pack observed in cigarette markets.

Second, we interpret the persistence of premium sales as reflecting a high degree of brand loyalty, which includes the influence of factors that create loyalty to the premium market segment. Our main analysis aggregates brands together into two compositive commodities premium and non-premium cigarettes. Aggregation is necessary because of the large number

\footnotetext{
${ }^{6}$ Our estimated treatment effects imply a 12 to 19 percentage point drop in the probability of purchasing a premium among smokers who live very near to a reservation. Given that 70 percent of smokers purchase premiums, this range of treatment effects means that roughly $17(=12 / 70)$ to 27 (= 19/70) percent of premium smokers living near a NAR stopped smoking premium cigarettes with the regime change, which leaves between 83 percent and 73 percent who would have remained brand loyal. As noted above, even in the absence of a regime change, year-on-year about 10 to 15 percent of premium smokers switch away from their specific brands. The brand switching in response to the regime change is on top of the background level of switching.
} 
of low-share brands in both market segments. For example, the NYS-ATS lists 31 separate brands by name as possible responses to the question about usual brand; 25 of the 31 brands have market shares of under five percent each. We aggregate brands together based on whether they are treated by the quasi-experiment we study. As a result, the prices of premium brands move together and the prices of non-premium brands move together, satisfying the conditions of the composite commodity theorem for aggregation (Deaton and Muellbauer 1980, pp. 120-122). Reductions in the use of the composite commodity called "premium" cigarettes in favor of the one called "non-premium" cigarettes necessarily involve brand switching. Because the quasi-experiment which we study does not provide price variation within premium and non-premium brands, we cannot study certain types of choices and brand loyalty such as between Marlboros and Camels. However, as a robustness analysis we estimate models of the choice between Marlboros and Senecas, which are the most popular premium and Native brands, respectively. We estimate that for smokers who lived very near a NAR, the regime change caused 25-40 percent of Marlboro smokers to switch to Senecas. Although the estimated brand-switching is higher than the 10-15 percent of annual brand-switching ordinarily observed among smokers, the majority of Marlboro smokers remained brand loyal.

The health consequences of smoking lend clear health economics and policy relevance to our findings. Smoking remains the leading preventable cause of death in the U.S. and is estimated to cause almost 500,000 deaths per year (U.S. Department of Health and Human Services 2014). The U.S. and many other countries impose high excise taxes on cigarettes to discourage smoking and to generate revenues (DeCicca, Kenkel, and Lovenheim 2020). Below, we estimate models of the impact of the NYS tax-regime change on adult smoking and discuss 
its impact on NYS cigarette tax revenues. Despite our estimates that the regime change had the unintended consequence of reducing sales of premium cigarettes, we do not find strong evidence that the regime change had its intended effects on smoking and tax revenues.

Beyond taxation, anti-smoking policies have long targeted cigarette marketing and advertising and restrict firms' ability to create brand loyalty. For example, the 1998 Master Settlement Agreement between the tobacco industry and State Attorneys General banned the advertising images of the Marlboro Man and Joe Camel. In 2012, Australia enacted a broad plain packaging law that requires a standardized pack appearance and the removal of all branding including colors, imagery, and logos; since 2012, a number of other countries including Canada and the United Kingdom have also enacted plain packaging laws. Although we do not study these policies directly, our new evidence on the strength of smokers' brand loyalty shed light on the potential for such policies to reduce smoking and perhaps improve public health.

The paper proceeds as follows: Section 2 develops a stylized model of cigarette brand choice which we use to formalize our definition of "brand loyalty" and to motivate our approach to heterogeneous treatment effects. We also discuss the regime change that provides our quasi-experiment and corresponding identification-related issues. Section 3 describes our data sets, key variables, and our analysis samples, while Section 4 lays out our empirical strategies. Section 5 presents our main estimates about cigarette brand loyalty, and Section 6 discusses additional evidence on the impact of the regime change on smoking behavior and tax revenues. Section 7 concludes the paper. 


\section{Theoretical Framework}

\section{A. A stylized model of cigarette product choice}

In this section we use a stylized model of a consumer's choice of cigarette product to explain how our approach compares to other empirical studies of consumer brand preferences and to motivate our empirical approach. Let the consumer's utility from cigarette product $\mathrm{j}$ be given by:

$$
U_{j}=\alpha_{j}-\gamma\left(P_{j}+T_{j}\right)-\delta D_{j}+\lambda A_{j}
$$

In equation (1), $\alpha_{j}$ is a product-specific intercept, $P_{j}$ is the untaxed price, $T_{j}$ is the cigarette excise tax, $D_{j}$ is the distance the consumer must travel to purchase product type $j$, and $A_{j}$ is an observable product attribute.

The consumer chooses product $\mathrm{j}$ over product $\mathrm{k}$ if the difference in utility is positive, where the utility gain $U^{*}$ is given by:

$$
U^{*}=U_{j}-U_{k}=\left(\alpha_{j}-\alpha_{k}\right)-\gamma\left(P_{j}-P_{k}+T_{j}-T_{k}\right)-\delta\left(D_{j}-D_{k}\right)+\lambda\left(A_{j}-A_{k}\right)
$$

As we discuss below, Equation (2) underlies our empirical model of the heterogeneous treatment effect of the tax-regime change on the probability consumers choose premiumbrand cigarettes. Before turning to that discussion, we now use equation (2) to discuss the role brand loyalty plays in the choice between premium- and Native-brand cigarettes.

Based on several lines of evidence we assume that the observable attributes $\left(A_{j}, A_{k}\right)$ of premium- and Native-brand cigarettes are virtually identical. First, although the cigarette market is segmented into so-called lights and regulars based on nicotine (the addictive component) and tar content, the nicotine and tar content does not vary systematically between 
premium and Native-brand cigarettes. ${ }^{7}$ Similarly, although menthol is a very noticeable flavor, most premium and Native brands are available in both menthol and non-menthol versions. Second, the manufacturing methods of the leading Native brands are comparable to the methods used to manufacture premium brands. The most common Native brand is Seneca, so we will discuss its manufacturing methods as an example. ${ }^{8}$ The Seneca brand, along with some other brands, are produced by Grand River Enterprises (GRE), which is a Native-owned cigarette company located in Ohsweken, Ontario, Canada. GRE generates millions of dollars in annual revenue, while exporting its cigarettes worldwide. According to news accounts, GRE produces cigarettes that use "grade $A$ " tobacco, high quality paper, and the latest in cigarette production technology. In more recent years, the tribes have invested even more in producing higher quality cigarettes, since they no longer sell premium brands like Marlboro that are manufactured off-reservation. Third, several Native-manufactured brands, including Seneca, attempt to mimic off-reservation premium brands, both in taste and nicotine/tar content. The text of one advertisement, seen in Figure 1, reads:

"Seneca brands are blends that compare to the taste of Marlboros. The Seneca blend is $100 \%$ quality natural tobacco with no harmful chemicals added. This unique blend gives the consumer a great flavour"9

\footnotetext{
${ }^{7}$ See http://www.econdataus.com/cigra.html, accessed June 4, 2020.

${ }^{8}$ Although a wide range of Native-manufactured cigarettes are sold on NYS NARs, in our NYS-ATS sample, Seneca is the choice of nearly three-quarters of smokers who regularly choose Native brands. The fraction who choose Senecas is similar across most parts of the state, suggesting that Senecas are sold on most or all of the NYS NARs. Other Native brands in our data include Smokin' Joes and Niagara. The company web pages for these Native brands also describe modern cigarette manufacturing methods. http://sjbrands.com/. https://www.ohserasemanufacturing.com/\#Our-Factory

${ }^{9}$ Like other Native-manufactured cigarette brands, Seneca features a full line of cigarette types including regular, menthol, menthol lights, light, ultra-lights, 100s, 120s, etc.
} 
Although we assume the observable attributes are virtually identical so the term $\delta\left(A_{j}-\right.$ $A_{k}$ ) drops out of equation (2), we allow for systematic differences in utility from premium versus Native brands; this is captured by the difference in product-specific intercepts $\left(\alpha_{j}-\alpha_{k}\right)$. Although the product-specific intercepts may reflect utility from unobservable (to the econometrician) product attributes, evidence from blind taste tests suggests a small role for true (as opposed to perceived) differences. This long-standing research literature finds that smokers can less-than-perfectly distinguish their own brands from others (Husband and Godfrey, 1934; Ramond et al., 1950; Littman and Manning, 1954; Prothro, 1953; Jaffe and Glaros, 1986). While some of these studies find that smokers can discern their regular brand from others at a rate greater than implied by chance, all imply substantially less than perfect discrimination. Most strikingly, a recent study by Skaczkowski et al. (2018) gave a group of smokers two types of cigarettes: one with a visible brand name and the other without any brand name. Smokers were then asked which cigarette they preferred. Despite the two cigarette types being identical, smokers rated the branded cigarette as having better taste. Because there were no true differences in attributes, these results point to other explanations for the perceived product-specific differences.

To sum up: Our working definition of brand loyalty is the difference in product-specific intercepts related to premium- and Native-brands. The product-specific intercepts capture consumer misperceptions of product quality (Bronnenberg et al. 2015), social visibility (Heffetz 2011), psychological costs of switching brands (Dube, Hitsch, and Rossi 2010), and advertising (Becker and Murphy 1993). Some, but not all, of these loyalty factors are common to all the brands that make up the composite commodity premium cigarettes. The fact that different 
premium brands are typically viewed as close substitutes for each other might reflect the common influence of quality misperceptions and social visibility that create loyalty to all premiums. ${ }^{10}$ Because we mainly study the choice between the composite commodities, we cannot identify brand-specific loyalty factors such as psychological switching costs and brandspecific advertising. We focus on consumer willingness to pay (WTP) for brand loyalty, where WTP is the utility difference (the difference in the product-specific intercepts) divided by the marginal utility per dollar $(\gamma)$ :

$$
W T P=\frac{\left[\left(\alpha_{j}-\alpha_{k}\right)\right]}{\gamma}
$$

\section{B. Heterogeneous treatment effect of the tax-regime change}

The treatment effect of the tax-regime change reflects how the utility gain from premium cigarettes varies between the pre- and post-periods. In the pre-regime change period, the tax on premium and non-premium brands is the same. In addition, premium and nonpremium brands are available on- and off-reservation, so the consumer does not face a different distance to travel to consume either type of cigarette. ${ }^{11}$ The utility gain from premium cigarettes in the pre-period simplifies to:

$$
U^{*} \mid \text { Pre-regime }=\left(\alpha_{j}-\alpha_{k}\right)-\gamma\left(P_{j}-P_{k}\right)
$$

\footnotetext{
${ }^{10} \mathrm{As}$ a result, we emphasize that our estimates of brand loyalty do not generalize to other shocks to brand prices. If most of the loyalty to premium brands reflects factors that are common to all premium brands, an exogenous increase in the relative price of, for example, Marlboros to Camels by $\$ 4.35 \mathrm{might}$ result in a larger reduction in brand loyalty than we estimate below.

${ }^{11}$ The consumer chooses whether or not to purchase cigarettes on a reservation by comparing the value of the tax savings $\gamma$ T to the travel costs of distance $\delta \mathrm{D}$. But in our stylized linear model, the utility gain from premiums is the same on- and off-reservation.
} 
In the post-regime, untaxed premium cigarettes are no longer available on reservations. Given the widespread availability of cigarettes off-reservation, the typical consumer faces a distance of approximately zero to purchase premiums. Non-premium cigarettes are available taxed off-reservation and untaxed on-reservation. We assume that the consumer makes the optimizing choice between paying $T_{k}$ off-reservation or traveling a distance of $D_{k}$ to purchase untaxed Native cigarettes from a reservation. The utility gain from premium cigarettes in the post-period is therefore given by:

$$
U^{*} \mid \text { Post-regime }=\left(\alpha_{j}-\alpha_{k}\right)-\gamma\left(P_{j}+T_{j}-P_{k}\right)+\min \left\{\gamma T_{k}, \delta D_{k}\right\}
$$

In utility terms, the treatment effect of the tax-regime change is the difference in the pre- and post-regime utility gains from purchasing premiums:

$$
\text { Treatment Effect }=-\gamma T_{j}+\min \left\{\gamma T_{k}, \delta D_{k}\right\}
$$

The treatment effect is predicted to be heterogeneous and depend upon the consumer's distance to a reservation. The negative treatment effect is largest (in absolute value) for a consumer who lives very close to a reservation; such consumers were most likely to have regularly purchased from NARs prior to the regime change that ended the availability of taxfree premium brand cigarettes. The treatment effect fades as the consumer's distance to a NAR increases. At longer distances where $\delta D_{k}>\gamma T_{k}$ the predicted treatment effect is zero.

Dividing equation (6) by the marginal utility per dollar ( $\delta$ ) provides a schedule of consumer WTP for brand loyalty. The fraction of consumers who live very close to a reservation and remain brand loyal after the regime change reveals the fraction of consumers with WTP $\geq$ $T_{k}=\$ 4.35$. The fraction of consumers who live a given distance $d$ and remain brand loyal reveals the fraction WTP $\geq \$ 4.35-(\delta / \gamma)$ d. Our empirical approach does not provide an 
estimate of the dollar value of distance traveled $(\delta / \gamma)$, but estimates from other research would allow us to plot out more of the WTP schedule for brand loyalty.

\section{The tax regime change and our identification strategy}

Identification of the heterogeneous treatment effect described above requires that: the tax-regime change is plausibly exogenous; and the consumer's distance to a NAR is plausibly exogenous. In this subsection we review evidence regarding these assumptions. Given these exogeneity assumptions our identification strategy exploits two quasi-experiments - the tax regime change and the quasi-random assignment of consumers to different distances from NARs. As a result, two groups of consumers form the untreated control group - consumers whose brand choices were observed prior to the regime change, and consumers observed postregime change who are located at such a long distance to a NAR that the regime change does not change their behavior.

The timing and background of the tax-regime change we study make it unlikely that it is econometrically endogenous, i.e. related to an unobserved factor influencing consumers' choices between premium and discount cigarettes. The tax-regime change was the result of a long history of legislation and litigation that began in 1988 when then-NYS Governor Mario Cuomo proposed collecting the NYS tax on cigarettes sold on NARs. The case went to the U.S. Supreme Court, which in 1994 ruled that NYS had the authority to collect taxes on reservation sales to non-tribal members. However, after those efforts to collect the taxes met with strong protests, in 1997 Governor Pataki announced that the taxes would not be collected. In 2010 legislation to collect taxes on reservation cigarette sales was passed but was again the subject of litigation through the fall of 2010 and into 2011. A NYS Supreme Court ruling allowed the 
state to collect taxes from cigarette wholesalers, which began in June 2011 under Governor

Andrew Cuomo. At that time, the Indian reservation retailers stopped purchasing cigarettes

from non-Indian wholesalers, creating the regime change we study. ${ }^{12}$ Neither side of the

protracted dispute focused on the sales of premium cigarettes: NYS focused on the potential

tax revenues, while the Indian tribes focused on tribal sovereignty and the employment and

sales revenue gains from reservation sales.

The consumer's distance to a NAR, which is the second key to our identification

strategy, is also plausibly exogenous. The location of NARs were established by long-standing

treaties, instead of based on any kind of current profit-maximizing decisions. Perhaps more

relevantly, it is plausible that individuals did not choose their place of residence based on

access to untaxed cigarettes, but on more common factors such as employment opportunities,

housing markets, and local public goods such as school quality. ${ }^{13}$ Our empirical model includes

NYS region fixed effects, so identification is from within-region variation in distance to a NAR

\footnotetext{
${ }^{12}$ The change was widely reported in the press. For example, an article that appeared in the Syracuse Post-Standard in July 2011 reported that: "The state Taxation and Finance Department confirmed that no taxed cigarettes had been sold to tribes since the law went into effect last month." (Coin 2011). Through a Freedom of Information Law request to NYS Department of Taxation and Finance, Kurti, von Lampe, and Johnson (2015) obtained official data on the shipments from non-Indian wholesales to Indian reservation retailers. They report that after the court ruling went into effect in June 2011, the shipments became "almost nonexistent." The shipments did not drop to zero because the court rulings allowed continued sales of untaxed non-Indian manufactured cigarettes to tribal members. Kurti et al. report that shipments dropped from 23.3 million cartons in 2010 to 29,000 cartons over the next two years combined (i.e., between June 21, 2011, and May 31, 2013).

${ }^{13}$ In the NHP data we use below, there are a small number of households that moved, as indicated by appearing in more than one zip code in the observations they contribute to the estimation samples. The residential choices of these movers might be more endogenous to the policy we study. The results reported below are not sensitive to dropping these households from the estimation samples, which is consistent with the argument that residential choices are exogenous. However, because only a small number of households moved, the results are not too informative on the endogeneity issue.
} 
that sells cigarettes. DeCicca, Kenkel, and Liu (2015) provide more discussion and evidence in support of the argument that distance is plausibly exogenous. ${ }^{14}$

\section{Data}

\section{A. General Information}

We use data from two sources. The first source is the 2003-2016 waves of the New York State Adult Tobacco Surveys (NYS-ATS), which is comprised of repeated cross-sections from quarterly surveys. In addition to extensive information on smoking-related attitudes, beliefs and risk perceptions, the NYS-ATS collects detailed information on the smoking behavior and purchasing patterns of New York State residents aged eighteen and older. These data are ideal for our study for several reasons. First, in addition to detailed smoking information, the NYS-ATS contains information on consumers' county of residence which, as described below, we use to construct a measure of a respondent's proximity to the nearest NAR that sells cigarettes.

Second, given that the data focus exclusively on NYS residents, they yield sample sizes sufficient to employ the empirical strategies we outline in Section 4. Finally, NYS-ATS data contain information on smokers' choice of cigarette brand, which we describe in greater detail below.

The second source of data is for NYS residents in the Nielsen Homescan Panel (NHP) from 2004 to 2016. Participants in the NHP use an in-home scanner to record all of their

\footnotetext{
${ }^{14}$ DeCicca, Kenkel, and Liu (2015) also use the NYS-ATS data. They follow standard practice and explore whether distance appears to be random in terms of observable characteristics. The logic is that the extent of randomness in observed characteristics is suggestive evidence supporting exogeneity. Conditional on the region fixed effects, they find no evidence of problematic heterogeneity associated with distance. In another empirical exercise, they use price data from the NHP to conduct falsification tests. Here the logic is that if there is problematic heterogeneity in consumer choices or market conditions, distance to a NAR should predict lower consumer prices in general, not just lower cigarette prices (in the pre-regime change period). They do not find any evidence that the prices paid for other frequently purchased items such as bread, eggs, and milk are systematically lower for consumers who live near NARs.
} 
purchases. Some households take part in the NHP for many years, while others join or exit the panel each year. The data contain detailed UPC-trip level information on price and quantity. We merge this to UPC product information which allows us to identify all household cigarette purchases. The data also include rich demographic and geographic information.

The NHP has several advantages that nicely complement our analyses that use the NYSATS. First, instead of self-reported data, the NHP measures cigarette brand choices based on scans of UPC codes. ${ }^{15}$ Second, the NHP contains 5-digit zip code information which allows us to compute more precise distances to NARs, which is the key variable for identifying heterogenous treatment effect. Third, although the full NHP sample includes all households in the data either before or after June 2011, we are also able to analyze a sub-sample that consists of a panel of households observed both before and after the policy change. Finally, like the NYS-ATS, the NHP covers a long pre- and post-intervention period which allows us to address a number of robustness concerns. The main drawback of the NHP is sample size. As a national sample, in a given year it contains around 250 to 600 smoking households from NYS. ${ }^{16}$

\footnotetext{
${ }^{15}$ The NHP panelists self-scan the UPC codes of their purchases, so the brand choice is still potentially measured with error if panelists do not scan all of their purchases. We see the NHP and NYS-ATS as complementary data sets in the sense that they use different methods to measure brand choice. ${ }^{16}$ We explored the possibility of expanding our sample to include non-NYS NHP households in border states near NYS NARs. However, due to the geographic distribution of NYS NARs, expanding the sample this way would not add many households. Furthermore, all non-NYS households received a smaller treatment than NYS households, because their home-state taxes were lower than the NYS tax of $\$ 4.35$ per pack -- \$1.60 per pack in Pennsylvania, \$2.70 in New Jersey, and \$0.40 in Connecticut until 2011 when it increased to $\$ 3.40$. In short, although adding these households would provide some additional variation, we gain relatively little and the variation that we gain is confounded with other differences.
} 


\section{B. Key Variables}

\section{Cigarette brand information}

We model whether consumers continue to purchase premium-brand cigarettes after they lose the opportunity to purchase them untaxed on NYS NARs. In the NYS-ATS, our dependent variable is a binary variable that equals one if a consumer purchases "premium" cigarettes and zero if the cigarette brand is considered "non-premium". We use the list from Hyland et al. (2005) to assign cigarette brands to these two categories, and all Native cigarette brands are considered "non-premium." 17 To assign these categories, we rely on the fact that the NYS-ATS asks smokers about their "usual" brand.

In the NHP, we observe purchases of 168 unique brands which we classify as premium or discount based on the list from Hyland et al. (2005), combined with the lists from Cornelius et al. (2013) and Nargis et al. (2014). The total household purchase shares of premium and discount brands are then aggregated to the monthly level. We use the monthly aggregated purchases to create a binary variable that equals one if the household purchases premium brands and equals zero if the household purchases discount brands. ${ }^{18}$ For 93 percent of household-month observations in our sample, households only purchased premium brands or only purchased discount brands. For the remaining seven percent of household-month

${ }^{17}$ Our definition of the composite commodity non-premiums includes non-Native non-premium brands. We use this definition because the responses to the NYS-ATS question about usual brand included the option "other brand," which might have been Native or non-Native. Below, we report results from models where the dependent variable measures the choice of a Native brand versus non-Native premium brands; in these models, non-Native produced non-premiums are dropped from the samples. ${ }^{18} \mathrm{All}$ results using the NHP are robust to using the fraction of premium sales for a household in each month as the outcome variable. We adopt the binary definition for ease of comparability with the NYSATS estimates. 
observations, we classified their usual brand as premium if their share of premium cigarette purchases that month was above the average premium share across the entire sample.

\section{Distance to a Native American Reservation (NAR)}

The NYS-ATS and the NHP provide information on respondents' county of residence. We use this information to compute distance to the nearest NAR that sells cigarettes using the ninedigit zip code of the NAR. For the NYS-ATS, we use the centroid of the individual consumer's county of residence as the starting point. For the NHP, we use the centroid of the household's 5-digit zip code as the starting point. We use the "fastest route" distance from Google Maps to measure distance between these two points.

\section{$\underline{\text { Reservation purchasing behavior }}$}

In addition to allowing us to compute a respondent's distance from a NAR that sells cigarettes, the NYS-ATS contains information on actual NAR purchasing behavior. ${ }^{19}$ Respondents are asked if they ever made "any reservation purchase" as well as whether such purchases occur "all the time, sometimes, rarely or never" (i.e., consumers are asked about the frequency of NAR cigarette purchase). While the former question is asked in all waves, the frequency of purchase question is omitted from some waves. As described in Section 4, we use these variables in the NYS-ATS to estimate a somewhat more structural version of our main model, which is inherently reduced-form in that it directly models the impact of the quasi-experiment. The goal of our more structural approach is to understand if those who are more likely to always purchase their cigarettes at NYS NARs are more affected by this policy change.

\footnotetext{
${ }^{19}$ The NHP does not contain such information.
} 


\section{Analysis samples and descriptive statistics}

We use three main analysis samples - the NYS-ATS sample, the NHP full sample, and the NHP panel sample. The NYS-ATS sample contains 9,732 consumers with complete information on their cigarette brand choices and county of residence information. The sample is from the 2003-2016 waves of the NYS-ATS. However, observations from 2008, 2009, and the first three quarters of 2010 were dropped because in those waves the NYS-ATS did not ask about brand choice. ${ }^{20}$ The NHP full sample is from 2004 to 2016 and includes 24,297 month-level observations generated from 2,024 unique households who purchased at least one pack of cigarettes during at least one of those calendar years. The NHP panel sample is limited to those households in the sample both before and after the regime change in June 2011. Because of rotation in and out of the NHP, the NHP panel sample consists of 308 households which generated 10,783 month-level observations.

As can be seen in Table 1, the NYS-ATS and NHP full samples are very similar, especially with respect to key variables. About 71 percent of smokers report their usual cigarette is a premium brand in the NYS-ATS, while roughly 68 percent of households with smokers are classified as premium users in the NHP. These premium shares are also consistent with other broader surveys of smokers' cigarette brand preferences over this time period (Cornelius et al., 2013). The average distance to a NAR that sells cigarettes is roughly 57 miles in the NYS-ATS

\footnotetext{
${ }^{20}$ While this limits our ability to fully understand the pre-regime period, the brand-choice question was asked once again in the Q4:2010 wave as well as the first two quarterly waves of 2011, which occurred prior to the NYS Supreme Court ruling that effectively ended the purchase of untaxed non-Native cigarettes on NYS NARs. As a result, even though our information on pre-period cigarette-brand choice is limited, we have information from just prior to the relevant regime change as well as in earlier years (i.e., 2007 and earlier).
} 
and 55 miles in the NHP. The fraction of NYS-ATS respondents who report making a reservation purchase within the past 12 months is 38 percent. Other covariates are substantially similar in the NYS-ATS and NHP data, but some differences exist. In particular, our NHP full sample is older, has more formal schooling and is less racially diverse than our NYS-ATS analysis sample. ${ }^{21}$

\section{Empirical Strategy}

\section{A. Primary Empirical Strategy}

Our main empirical strategy is based on equation (6). We study the quasi-experiment created by the tax-regime change and allow for heterogeneous treatment effects that depend on consumers' distances to a NAR. We note that consumers who face long distances such that $\delta D_{K}$ $>\nu T_{K}$ are predicted to never purchase cigarettes from reservations and thus can be considered to form a second untreated control group which should be unaffected by the tax-regime change. The following reduced-form equation generates our main estimates:

$$
\text { PREMIUM }_{i c t}=\beta_{1} \text { POST }_{i t}+\beta_{2} \text { DISTANCE }_{i c t}+\beta_{3}\left(\text { POST }_{i t} * \text { DISTANCE }_{i c t}\right)+X_{i c t} \gamma+\varepsilon_{i c t}
$$

In equation (7), the dependent variable, PREMIUMict, equals one if consumer (in the NYS-ATS) or household (in the NHP) i in county (in the NYS-ATS) or zip code (in the NHP) c at time t's usual brand is categorized as a premium brand and zero otherwise, DISTANCE ict $_{\text {represents the }}$ distance in hundreds of miles from the individual's residence to the nearest NAR that sells cigarettes, and $\mathbf{P O S T}_{i t}$ is an indicator variable for data gathered after the June 2011 regime

\footnotetext{
${ }^{21}$ Note that some of the categories in Table 1 differ slightly across the two data sets. In the NHP, households can report the presence of a female head of household, a male head of household, or the presence of both. The NHP does not report information on whether the household heads are Hispanic. The NHP also reports slightly different income categories: in particular, the two top brackets are $\$ 60 \mathrm{k}-$ $\$ 99 \mathrm{k}$ and $\$ 100 \mathrm{k}$ or more.
} 
change. Standard errors for this and all models estimated are clustered by county of residence in the NYS-ATS and at the zip code level in the NHP.

Note that $\beta_{1}$ captures the impact of the policy change on those who live very close to a NAR that sells cigarettes. ${ }^{22}$ In the limit, it represents the impact of the regime change for those who live zero miles away from such a NAR. In principle, consumers living closest to a NAR that sells cigarettes represent the strongest "treatment", i.e., those for whom the regime change is most relevant given their proximity to a NAR. $\beta_{3}$ captures the difference in the impact of the regime change when the treatment becomes less relevant (i.e., as respondents live further from a NAR that sells cigarettes). By estimating $\beta_{1}$ and $\beta_{3}$ we allow for heterogenous treatment effects; the marginal effect of the regime change at distances strictly greater than zero is given by $\beta_{1}+\beta_{3} *$ DISTANCE. When discussing our results, we find it convenient to refer to the estimated treatment effect for consumers who live very close to a NAR because that effect corresponds the estimates of $\beta_{1}$ reported in the Tables; those consumers do not play any special role in our empirical estimates.

Other covariates are as follows: $\mathbf{X}$ is a set of standard socio-demographic controls including age, race, education, household income, marital status, as well as the current NYS cigarette excise tax. The excise tax is a fixed amount per pack, so off-reservation the tax is the same on premiums and non-premiums. However, the tax might affect brand choices via

\footnotetext{
${ }^{22}$ Some consumers who live very close to a NAR are Native Americans, but the numbers are too small to drive our empirical results. Only 1.3 percent of our NYS-ATS sample identify as Native American/Alaskan and, of these, only nine of these individuals (i.e., 0.1 percent) live within 10 miles of a NAR that sells cigarettes. To comply with earlier U.S. Supreme Court decisions, when NYS began collecting the cigarette tax on reservations, it created an exemption system to allow tribal members to not pay NYS taxes. Because tribal members can still purchase tax-free premium cigarettes, the small number of tribal members included in our data would tend to slightly bias our treatment effect estimate towards zero.
} 
substitution where the reservation tax break reduces the relative price of premiums versus discount cigarettes (Sobel and Garrett, 1997, DeCicca, Kenkel, and Liu 2015). The set X also includes region fixed effects and a linear time trend to account for trends in cigarette brand choices that are common across counties in NYS. ${ }^{23}$ As a result, our models are identified from within-region variation in distance to a NAR that sells cigarettes. ${ }^{24}$

We present results from three additional specifications: first, we re-estimate equation (7) replacing our PREMIUM dependent variable with one that indicates whether an individual (NYS-ATS) or household (NHP) purchases Native-brand cigarettes. We do this to better understand whether our main estimates are driven by consumers moving to the still-untaxed Native-produced brands and not some other, spurious form of brand switching. Second, to explore socioeconomic heterogeneity we estimate separate models by age group, education group, and income group. Third, we use versions of equation (7) to estimate a set of placebo tests. We want to ensure that our findings represent the impact of the regime change and do not represent a longer-standing secular trend in cigarette brand choices among NYS consumers.

\footnotetext{
${ }^{23}$ Because we study a single state-wide policy change, collinearity prevents us from following the standard practice of including survey wave dummies to model time effects more flexibly. We have explored two alternative specifications: a quadratic time trend and including year effects. When year effects are included, identification is from within-year variation in the policy environment, and the only year with such variation is 2011. The results from these alternative specifications -- reported in Appendix Table A1 - are similar to the main results reported in Table 2.

${ }^{24}$ We obtain similar results from an alternative specification possible in the NHP data, where we replace the NYS region indicators with a set of county indicators (see Appendix Table A2). In the NHP data distance to a NAR is based on the household's zip code, so this specification identifies the effect of distance from within-county variation. This specification is not possible in the NYS-ATS data, where distance is measured based on the respondent's county of residence.
} 


\section{B. An alternative empirical strategy}

While equation (7) represents our main model, we employ another related empirical strategy and allow the impact of the regime change to vary by the predicted probability that the consumer always purchases their cigarettes on a NAR. This strategy, which we can only implement in the NYS-ATS, is motivated by the idea that consumers who always purchase their cigarettes on a NAR are the most likely to be affected by the regime change. To accomplish this, we first estimate the model:

$$
N_{A R P A} \text { ict }=\delta \text { DISTANCE }_{\text {ict }}+X_{\text {ict }} \gamma+\varepsilon_{\text {ict }}
$$

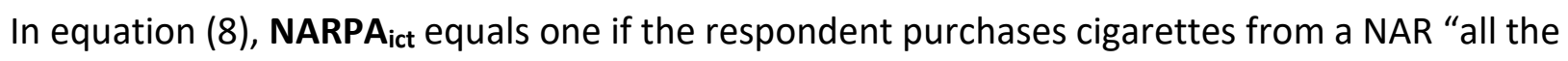
time" and zero otherwise, DISTANCE ict $_{\text {is }}$ defined as above and $\mathbf{X}_{\text {ict }}$ also includes the same set of controls as in equation (7).

Information on the frequency of cigarette purchase from a NAR is missing from some waves of the NYS-ATS; therefore, we use available data to estimate equation (8) and then use the coefficient estimates from this model to compute corresponding predicted probabilities for the entire sample. Moreover, we use only data prior to the regime change in June 2011 to generate these predicted probabilities. ${ }^{25}$ We then estimate the following equation stratified along quintiles of the predicted probability distribution described above:

$$
\text { PREMIUM }_{\text {ict }}=\rho \mathrm{POST}_{i t}+\mathrm{X}_{\text {ict }} \theta+\tau_{\text {ict }}
$$

To be clear, we estimate equation (9) separately for each of the five quintiles of the predicted probability distribution of the variable NARPA $A_{\text {ict. }}$ Our hypothesis is that the brand choices of

\footnotetext{
${ }^{25}$ This is because NAR purchasing and the decision to purchase a premium brand are jointly endogenous outcomes after the regime change since the tribes stopped selling non-Native cigarettes on NARs.
} 
those with higher predicted probabilities of reservation purchasing are more likely to be affected by the regime change. In other words, we expect $\rho$ to be systematically negative for quintiles which include observations with higher predicted probabilities of always purchasing cigarettes on a NAR. This approach also allows us to estimate heterogeneous treatment effects, here by the predicted probability of always purchasing on a NAR.

\section{Results}

Below, we present estimates from models described in the previous section. We first discuss our main results from both the NYS-ATS and NHP data sets, and then discuss additional estimates that support their causal interpretation. Overall, while our estimates imply a nontrivial amount of brand switching, a strong majority of premium consumers do not switch from premium-brand cigarettes after losing an untaxed source of them (i.e., after facing a much higher price for them), and we characterize this as a high degree of brand loyalty.

\section{A. Impact of the regime change on cigarette brand choice: Main estimates}

Table 2 presents estimates from our main specification (Equation 7) which uses a heterogeneous treatment effects framework to model the impact of the regime change on the purchase of premium-brand cigarettes. The specification allows the impact of the regime change to vary by distance from one's county of residence to a NAR that sells cigarettes.

The first column of Table 2 presents estimates from the 2003-2016 waves of the NYS-

ATS. After premium cigarettes were no longer available tax-free on NYS NARs, for those living very close to a NAR we find that the regime change lowered the fraction of premium purchasing by roughly 18 percentage points (i.e., $\beta_{1}=-0.1841$ ). At the average distance from a NAR of about 57 miles, the implied effect is a 6.6 percentage point decrease in the probability 
of premium purchases. Given that roughly seventy percent of consumers chose premium-brand cigarettes in the pre-regime change period, our estimate implies that 26 percent of premium consumers living very close to a NAR switched to a non-premium brand; at the sample average distance from a NAR roughly nine percent of premium consumers switched to non-premiums.

We present results from the 2004-2016 waves of the NHP in columns 2 (NHP full sample) and 3 (NHP panel sample). The findings are substantially similar to those generated using the NYS-ATS. We find evidence that the regime change reduced premium cigarette brand purchases and that the impact varies with the household's distance to an NAR. In particular, among households living very close to an NAR, in our "full sample" (Column 2) we find that the regime change reduced the fraction of smoking households that purchased premium-brand cigarettes fell by roughly twelve percentage points (i.e., $\beta_{1}=-0.1150$ ), while in our "panel sample" (Column 3) we find a corresponding reduction of roughly fifteen percentage points (i.e., $\left.\beta_{1}=-0.1500\right)$. These estimates imply a reduction of between 17 and 23 percent, relative to the fractions of the samples that use premiums (the dependent means listed in the relevant columns of Table 2). Like the NYS-ATS estimates, these two NHP estimates suggest that the regime caused a substantial movement away from premium-brand cigarettes.

Two aspects of our findings are noteworthy. First, the coefficients on the interaction term $\left(\beta_{3}\right)$ imply that the impact of the regime change declines to approximately zero at distances between 40-50 miles (NHP) and 90 (NYS-ATS). Though they differ somewhat, perhaps due to aforementioned differences in how distance is computed in each data set, we believe 
that these are reasonable distances at which to expect any systematic effects to have vanished. ${ }^{26}$

Second, and much more importantly, while our estimates imply substantial brand switching, they also suggest a strong degree of brand loyalty. In the NYS-ATS and both NHP samples, the estimates imply that among consumers living very close to a NAR, about threequarters of premium users did not make such a switch in spite of a very large implied price increase. By comparison, the descriptive marketing study by Dawes (2014) finds that smokers of Marlboros and other large brands show high brand loyalty; the average year-on-year stability in high loyalty to the major brands is 86 percent. The quasi-experiment we study disrupted brand loyalty; the fraction loyal to premiums is much lower than the 86 percent that would be expected to remain loyal to the specific brands that make up the composite commodity. Combining our estimate of the fraction that stayed premium loyal with the evidence from Dawes (2014), we estimate that among premium smokers with the most to gain from switching, 63.5 percent remained loyal to the specific brands that form the composite commodity premium cigarettes. That is, even with reasonable substitutes available at much lower prices, a majority of premium consumers continue to purchase premium-brand cigarettes after the tax-

\footnotetext{
${ }^{26}$ We expect the regime change to have no effect on consumers who never purchase cigarettes on NARs in the pre-regime. The break-even distance to make a NAR purchase, i.e. for a NAR purchase to increase consumer utility, is where the utility cost of traveling that distance equals the tax savings. Assuming that the average NAR purchase is one carton of 10 packs, each purchase saves $\$ 43.50$. If the break-even distance is about 45 miles, the implied cost per mile is $\$ 0.97$ per mile. If the break-even distance is about 90 miles, the implied cost is $\$ 0.48$ per mile. In 2011, based on the fixed and variable costs of operating an automobile the IRS mileage rate was $\$ 0.51$ per mile (https://www.irs.gov/pub/irs-news/ir-10-119.pdf (accessed June 18, 2020).
} 
regime change. Indeed, in the immediate vicinity of a NAR, non-switchers are consumers who are willing to pay at least $\$ 4.35$ per pack more to avoid switching to a Native-produced brand. The willingness to pay to avoid brand switching could be less than the $\$ 4.35$ tax per pack if there were strategic pricing responses to the regime change. ${ }^{27}$ Off-reservation retailers might have lowered prices after the regime change to compete with NAR retailers; or on-reservation retailers might have increased prices to exploit their market power. To explore the possibility that the regime change decreased off-reservation prices, we examined the self-reported cigarette price paid by NYS-ATS respondents who reported making no NAR purchases (see Appendix Table A3). The estimated impact of the regime change on off-reservation cigarette prices is a small increase which is not statistically significantly different from zero. The lack of a strategic price response by off-reservation retailers is consistent with DellaVigna and Gentzkow (2019), who find that most food, drug, and mass merchandise chains charge near uniform prices for a broad range of goods despite variation in local competition. ${ }^{28}$ To explore the possibility that the regime change increased on-reservation prices, we examined the price paid by NYS-ATS respondents who reported that they always make NAR purchases (see Appendix Table A3). The estimated impact of the regime change is again small and statistically insignificantly different from zero. The lack of a strategic price response by on-reservation

\footnotetext{
${ }^{27}$ We thank an anonymous referee for suggesting the possibility of strategic pricing responses. It also should be noted that the derivation of equation (7) assumes no strategic price responses. ${ }^{28}$ In contrast, using national data with off-reservation local cigarette prices from 1976-2003, Carpenter and Mathes (2016) find lower prices in cities near Native American casinos (a proxy for NARs that sell cigarettes). Our NYS data might not provide sufficient statistical power to detect price effects of the magnitude they estimate. Another explanation for the different results is that the regime change we study might have created smaller or even off-setting incentives for local price competition. Although publicity about the regime change might have increased competitive pressures for off-reservation retailers, the regime change might instead have reduced competitive pressures because it reduced the types of cigarettes available untaxed on NARs.
} 
retailers is consistent with DeCicca, Kenkel, and Liu (2015), who present evidence that on most NARs there is substantial competition between Native-owned retail establishments.

Implicit in the Table 2 models is the assumption that consumers who previously purchased tax-free premium-brand cigarettes on NARs switched to still-untaxed Native brands. In Table 3, we present estimates that test this mechanism directly, and indeed these estimates are very similar in magnitude to our estimates in Table 2, though as expected, they are opposite in sign. In the NYS-ATS we find an increase of 20 percentage points (i.e., 0.1962). This is nearly identical to our corresponding brand switching estimate from the NYS-ATS in Table 2 which was -0.1841. In the NHP, we also see a similar pattern. In the full NHP sample, the estimated coefficient is 0.1270 (versus -0.1150 in Table 2 ), while it is 0.1190 in the NHP panel sample (versus -0.1500 in Table 2). These findings strongly imply that the switching we detect in our brand choice models is driven by the availability of still-untaxed Native-produced cigarettes, as opposed to other, potentially spurious premium-brand to non-premium brand switches. Moreover, the existence of such switchers implies that a non-trivial fraction of NYS consumers do indeed view Native-brand cigarettes as reasonable substitutes for the premium brands that many respondents had previously smoked. Ultimately, however, our main results still imply that the majority of premium consumers show substantial brand loyalty.

As a further step to explore the type of brand switching that occurred due to the regime change, we have estimated models of the choice between two specific brands - the most popular premium brand Marlboro, and the most popular Native brand Seneca. To estimate the models, we restrict the samples to only include consumers who choose Marlboros or Senecas; otherwise, the specification is the same as used in Table 2 . The results, which are reported in 
Appendix Table A4, strongly corroborate the results in Table 2. In the NYS-ATS data, we estimate that for smokers who lived very near a NAR, the regime change caused 40 percent of Marlboro smokers to switch to Senecas. In the NHP-Full and NHP-Panel data, the corresponding estimates are that the regime change caused about 25 percent of Marlboro smokers to switch to Senecas. Although the estimated brand-switching is higher than the $10-15$ percent of annual brand-switching ordinarily observed among smokers, despite the tax-regime change, the majority of Marlboro smokers remained brand loyal.

\section{B. Impact of the regime change on cigarette brand choice: Socioeconomic heterogeneity}

Although to this point we have focused on the effects of the regime change, other results from the Table 2 models show that premium cigarette use is more common among younger smokers, smokers with more education, and higher-income smokers. To further explore this heterogeneity, we estimate separate models by age (under 45 years old versus 45 and over), education (high school graduate or less versus some college or more), and income (household income under $\$ 30,000$ versus $\$ 30,000$ income or over). A lack of larger samples prevents us from further disaggregating into smaller groups, and we chose the groupings to correspond as closely as possible across the two data set.

The results in Table 4 suggest that young smokers, smokers with more education, and higher-income smokers responded more to the regime change than older smokers, lesseducated smokers, and lower-income smokers, respectively. In each case, the sub-group that responded more also has the higher premium share. After subtracting the estimated treatment effects for smokers who live very close to a NAR from the group means, the premium shares for the groups tend to converge. One interpretation of the pattern of results is that the 
demographic groups with relatively high premium shares included more people with weaker brand loyalty, so they responded more to the regime change.

C. Impact of the regime change on cigarette brand choice: Estimates from the alternative empirical strategy

In addition to the reduced-form approach in our main analysis, we next employ a slightly more structural approach to understand the impact of the regime change on consumers' brand choice. This analysis uses a measure only available in the NYS-ATS. As described above in the empirical methods section, we estimate equation (9) separately for each of the five quintiles of the predicted probability distribution of whether one "always" purchases cigarettes on a NAR. The cutoff between highest quintile and 2 nd highest quintile is 0.34 , so reservation purchases are predicted to be quite common in the highest quintile. The cutoff points for other quintiles are $0.17,0.08$, and 0.03 , so reservation purchases are predicted to be almost zero in the lowest quintile.

The results of the alternative empirical strategy (equation 9) are presented in Table 5. Consistent with our expectations, systematically negative estimates of the regime change are found only in the upper quintiles, while no such evidence exists in lower quintiles predicted to have a very low probability of always purchasing their cigarettes on a NAR. Moreover, the first quintile exhibits the largest estimate of the regime change, at about 13 percentage points (i.e., 0.1299), which implies that 26 percent of premium smokers switched, similar in magnitude to 
our main estimates from both the NYS-ATS and the NHP. ${ }^{29}$ As such, it is also consistent with a high degree of brand loyalty.

\section{Placebo tests and additional corroborating evidence}

Having established that the implied brand switching we presented in Table 2 is likely driven by increases in the purchase of still-untaxed Native-brand cigarettes, we turn to whether our estimates might be due to existing underlying brand choice trends instead of the regime change. To explore this question we conduct placebo test versions of the Table 2 models, and we explore the parallel trends assumption in a difference-in-difference empirical approach.

In Table 6, using both the NYS-ATS and NHP, we present estimates from placebo regressions that assign the date of the actual regime change (i.e., June 2011) as having occurred at five other artificial dates. In the NYS-ATS, we assign artificial dates as: June 2004, 2005, 2006, 2007 and 2010, while in the NHP we assign them as: June 2006, 2007, 2008, 2009 and $2010 .{ }^{30}$ To avoid any impact of the regime change, we restrict the sample in these models to observations collected prior to June 2011. Our estimates of the treatment effect of the June 2011 regime change might be spurious if there were a non-linear negative trend away from premium brands, which could be picked up by the placebo tests. ${ }^{31}$

\footnotetext{
${ }^{29}$ In a related exercise, we re-estimated our Table 2 model after dropping from the sample consumers who reported having never made cigarette purchases on a reservation, because they form another control group that was untreated by the regime change. In the restricted sample, for those living very close to a NAR we find that the regime change reduced the fraction of premium purchasing by 34 percentage points, compared to 18 percentage points in the full sample (see Appendix Table A5). ${ }^{30}$ As explained above in the data description, observations from the 2008 and 2009 NYS-ATS are dropped because those waves did not ask about brand preference. As a result, we cannot run placebo tests for those years.

${ }^{31}$ Our main models in Table 2 control for a linear trend, so only a non-linear negative trend would be problematic. As noted above in footnote 23 , although we are not able to use fully flexible controls for time effects, the results in Table 2 are not sensitive to several alternative specifications of time effects (see Appendix Table A1).
} 
Reassuringly, none of the estimates in Table 6A of the placebo treatments in the NYSATS data is negative and statistically significant. However, as can be seen in Table 6B, the estimate from the placebo regression in the NHP data that assigns June 2010 as the artificial date is positive and significant, which implies that premium cigarette purchasing actually increased just prior to the actual regime change, one year later in June 2011. Typically, placebo regressions are estimated to detect movements in the same direction of the expected policy effect but that precede the policy implementation, because the concern is that early secular trends may be driving estimated causal effects. In this case, in one dataset we find evidence of a trend that runs counter to our main finding that premium-brand purchases decreased after the regime change. To explore the positive placebo effect more, in an additional analysis we reestimate our main models after we drop NHP observations collected between July 2010 and May 2011. In the results (presented in Appendix Table A6) we continue to find evidence of brand switching due to the regime change, but an even greater level of brand loyalty.

One explanation is that the positive June 2010 placebo effect reflects stockpiling in anticipation of the June 2011 regime change. ${ }^{32}$ However, the complicated legal history might have made it hard for consumers to anticipate the exact date of the regime change and stockpile cigarettes. ${ }^{33}$ The June 2011 regime change we study traces back to a 2006 regulatory scheme that was never enforced. In June 2010, NYS codified the 2006 regulatory scheme; it was scheduled to take effect September 1, 2010, but legal challenges in several NYS judicial Districts

\footnotetext{
${ }^{32}$ We thank an anonymous referee for suggesting that we examine stockpiling.

${ }^{33}$ The complicated legal history is described in more detail here: https://tobaccopolicycenter.org/tobacco-control/tobacco-litigation/collecting-cigarette-taxes-fromnative-american-retailers/
} 
meant that it was not implemented until June 2011. To explore stockpiling further, we estimate models of the fraction of consumer purchases made by the 10-pack carton instead of a single pack. The fraction of carton purchases did not increase in June 2010 (as might have been suggested by the positive June 2010 placebo effect) or September 2010 (as might have been suggested by the scheduled regime change). ${ }^{34}$ Smokers in different judicial Districts might have stockpiled at different dates throughout 2010-2011 in reaction to the different court cases, but we are unable to find conclusive evidence of this in our data. ${ }^{35}$

To further explore trends in brand choice that might be independent of the regime change, we re-specify our model and adopt a difference-in-difference empirical approach. In the difference-in-difference specification we can examine whether the trends in brand choice were parallel in the treatment group and the control group. For this approach we define the treatment group to be consumers in roughly the lowest quarter of distance from a NAR who would be expected to be most affected by the regime change; we define the treatment group to be consumers in roughly the highest quarter of distance from a NAR who would be expected to be affected the least. We drop consumers at intermediate distances from a NAR because they were a weakly treated group. ${ }^{36}$

\footnotetext{
${ }^{34}$ See Appendix Table A7.

${ }^{35}$ The official New York State Department of Taxation and Finance data on cigarette shipments to NARs also do not show any obvious signs that retailers stockpiled cigarettes. Shipments in 2010 were about the same as in 2009. Shipments in 2011 were 41 percent of 2010 shipments, which is consistent with steady shipments through the first half of 2011 until shipments stopped in June.

${ }^{36}$ We defined the treatment and control groups based on an admittedly somewhat subjective comparison of travel costs and potential savings from a NAR purchase; the exact cutoffs also reflect the distribution of distances from NARs in our data The broad patterns of results are not sensitive to the use of different cutoffs or to changing the definition of the treatment and control groups to include the weakly treated group.
} 
The difference-in-difference results support out Table 2 findings; we estimate that the regime change caused a statistically significant reduction in the choice of premium cigarette brands in the treatment group who lived close to a NAR (see Table A8). Moreover, we find that the pre-regime change trends were not statistically significantly different in the treatment and control groups, supporting the parallel trends assumption (see Table A9). Visual inspection of the data shows no systematic differences in the pre-regime change trends in the choices of premium cigarettes, Native-brand cigarettes, and non-premium non-Native brand cigarettes (see Appendix Figures A2-A7). ${ }^{37}$ In the NHP data, there is an upward trend in premium use starting around 2010, consistent with the June 2010 positive placebo effect. The positive trend might reflect stockpiling in anticipation of the regime change. Post-regime change, there is a steady and growing decline in premium purchases through 2016 . This is evidence that the estimated treatment effect is not a temporary decline due to stockpiling prior to the regime change. Post regime change, Native-brand cigarette purchases continue to trend upwards. The post-change trends provide evidence that the treatment effect is growing over time, perhaps suggesting that consumers learned that Native brands are an acceptable and less costly substitute for premium brands.

\footnotetext{
${ }^{37}$ As noted above, the NYS-ATS did not collect information on brand choice from 2008 through the third quarter in 2010. From 2005-2007 there is an upward trend in the choice of Native-brand cigarettes, but between the fourth quarter of 2007 and the fourth quarter of 2010 the fraction who chose Native cigarettes only increased by a little more than one percentage point, from 13.9 percent to 15.2 percent.
} 


\section{Impact of the Regime Change on Smoking Behavior and Tax Revenues}

In this section, we shift the focus from brand loyalty and consider possible impacts of the regime change on adult smoking behaviors and NYS tax revenues. ${ }^{38}$

\section{A. Smoking Behaviors}

Instead of switching brands, some smokers might have responded to the regime change on different margins and quit smoking or reduced their daily consumption. To explore this, we examine four smoking behaviors measured in the NYS-ATS - past-year quitting, past-year quit attempts, the intention to quit within the next six months, and the number of cigarettes smoked per day. We estimate models that parallel the specification of the Table 2 models (equation 7) and include the same explanatory variables.

In Table 7 we find mixed evidence that the regime change affected smoking behavior. We interpret the results in Table 7 in light of our identification strategy, which as discussed above exploits two quasi-experiments - the tax regime change and the quasi-random assignment of consumers to different distances from NARs. Among smokers who live very close to a NAR, we estimate that the regime change had very small and statistically insignificant effects on past-year quitting and past-year quit attempts, and a small but statistically significant effect on quit intentions. The estimated 4.1 percentage point increase in quit intentions is

\footnotetext{
${ }^{38}$ In general, cigarette tax policies may also affect youth smoking initiation. In our data, we are unable to explore the impacts on youth smoking. The NYS-ATS is restricted to adults, and in the NHP, the unit of observation is the household, so we are unable to determine if household cigarette purchases were smoked by an underage household member. However, the tax regime change we study is unlikely to have had an important impact on youth smoking. Most youth will be unable to drive to NARs to purchase untaxed cigarettes before or after the regime change. Moreover, on- and off-reservation cigarette sales to minors are illegal; most youth obtain their cigarettes through social sources instead of retailers. The availability of untaxed cigarettes might increase the supply through social sources, so the regime change could indirectly affect youth smoking through that channel.
} 
about six percent of the sample mean; the effect is estimated to fade with distance to a NAR. Unexpectedly, we estimate that for smokers who live very close to a NAR, the regime change is associated with smoking about 1.5 more cigarettes per day. However, the coefficient on the interaction term with distance is not statistically significantly different from zero, which implies that the unexpected positive treatment effect does not fade with distance. In the models of past-year quits and quit attempts, although we do not find un-interacted treatment effects, the coefficients on the distance interaction term are statistically significantly different from zero. In short, the two quasi-experiments in our data do not show consistent impacts on three of the four smoking behaviors we study; i.e., the results in Table 7 do not provide consistent evidence that the regime change had heterogenous treatment effects which are strongest close to a NAR and fade with distance.

\section{Tax Revenues}

Aside from discouraging smoking, the main policy rationale for the regime change was to increase cigarette tax revenues. Figure 2 shows NYS cigarette tax revenues from 1987 through 2016. Tax revenues sharply increased following the $\$ 0.55$ tax hike in 2000 , the $\$ 1.25$ tax hike in 2008 , and the $\$ 1.60$ tax hike in 2010 . Given the consensus from prior econometric estimates that cigarette demand is price-inelastic, these increases in tax revenues are expected. In contrast, the regime change in July 2011 was not successful in increasing cigarette tax revenues. Tax revenues are almost flat the first year after the regime change, and then slightly decline from 2012 through 2016.

Based on our estimates that many smokers remained loyal to premium brands and that smoking behavior did not change much, the regime change might have been expected to 
substantially increase NYS cigarette tax revenues. In the two years prior to the regime change, untaxed shipments from non-Indian premium cigarette wholesalers to NYS NARs were a little more than 50 percent as large as taxed shipments to non-Indian NYS retailers. ${ }^{39}$ During the transition year of 2011, shipments to NARs drop to about 27 percent of taxed shipments; from 2012 - 2015 (the latest available data) shipments to NARs are a fraction of one percent. If, after the regime change, all smokers remained loyal to premium brands, after the transition year NYS tax revenues would be expected to increase by at least 50 percent. Based on the results reported in Table 2, we estimate that the average impact of the regime change was to decrease premium use by 6.6 percent. ${ }^{40}$ This leads to the prediction that the regime change should have increased NYS cigarette tax revenues by 43.4 percent.

The impact of the regime change on cigarettes sold in the illegal New York City street market may help partly explain why NYS tax revenues did not increase as much as might have been expected. Kurti, von Lampe and Johnson (2015) collected discarded cigarette packs in the South Bronx before and after the regime change. Prior to the regime change, 42 percent of the discarded packs had no tax stamps; most of these were probably cigarettes originally sold untaxed on NY NARs. After the regime change, the fraction of discarded packs with no tax stamps dropped to 6.2 percent, and there was a corresponding increase in the fraction of discarded packs with out-of-state tax stamps. Kurti et al. conclude that the supply of cigarettes

\footnotetext{
${ }^{39}$ Marin Kurti graciously shared the data on shipments to NYS NARs, which he obtained through a Freedom of Information request to the NYS Department of Taxation and Finance. Kurti, von Lampe, and Johnson (2015) provide more discussion of the impact of the regime change on cigarette shipments to NARs.

${ }^{40}$ To predict the average impact of the regime change, we evaluate the Table 2 results at the average distance from a NAR. In the NYS-ATS the average distance from a NAR is 0.573 hundred miles, so from the Table 2 results the predicted decrease in premium use is given by: $-0.1924+0.221 \times 0.573=0.066$.
} 
to the New York City street market shifted from NYS NARs to vendors in low-tax states, without a change in the overall prevalence of illegal cigarettes. Anecdotal media reports suggest that prior to the regime change, the two NARs located on Long Island were the major suppliers of cigarettes sold illegally on the street in New York City (e.g. Saul 2008). Prior to the regime change, shipments from non-Indian premium cigarette wholesalers to the two Long Island NARs were about 17 percent as large as taxed shipments. Taking into account the combined effects of reduced premium use and the shift in the supply of New York City street cigarettes leads to the prediction that the regime change should have increased NYS tax revenues by 26.4 percent. $^{41}$

Increases in cigarette purchases from other states or over the internet might also help explain why NYS tax revenues did not increase by as much as might have been expected. Previous research estimates that cigarette purchases across state borders respond to the existence and size of cross-border tax differentials (Harding, Leibtag, and Lovenheim 2012, DeCicca, Kenkel, and Liu 2013). After untaxed premium cigarettes were no longer available on NYS NARs, some NAR purchasers might have shifted their purchases to nearby lower-tax states such as Pennsylvania and New Jersey. Consistent with substantial border-crossing by former NAR purchasers and by other smokers, after the June 2010 tax hike the total volume of

\footnotetext{
${ }^{41}$ For this prediction, we assume that the combined effects of reduced premium use and the shift in the supply of New York City street cigarettes are additive. We interpret our models of premium use as reflecting consumer purchases of untaxed reservation cigarettes for their own consumption, which was legal. In contrast, the New York City street market involves suppliers making illegal purchases of untaxed reservation cigarettes for re-sale to smokers on the street. We assume that the combined effects are additive because we do not think that our empirical model picks up the impact of the illegal street market. To corroborate this, we re-estimated our model after dropping observations from New York City. The sample restriction did not change the results (see Appendix Table A10).
} 
cigarette sales in NYS fell in 2011 and 2012 by more than would be predicted by consensus

price-elasticity estimates. ${ }^{42}$ When we extend our empirical model of premium use, we find no evidence that border crossing increased after the regime change, but this might be due to lack of statistical power. ${ }^{43}$

\section{Conclusions}

In this paper we quantify consumer brand loyalty, using quasi-experimental variation in the prices of premium brand cigarettes relative to Native brands. Using data from the NYS-ATS and the NHP, we estimate the demand response for premium brand cigarettes from a near doubling in price. In our main specification, we find that for consumers who live very close to an Indian reservation, the regime change reduces the probability of purchasing a premium brand cigarette by about 18 percentage points in the NYS-ATS and by between 12-15 percentage points in NHP data. Although there is substantial brand switching, our results show that cigarette consumers display a high degree of brand loyalty. Many premium-brand consumers

\footnotetext{
${ }^{42}$ Our comparison of the changes in observed volume to predicted changes in volume uses the same logic as more systematic "residual methods" for measuring the extent of trade in untaxed cigarettes (National Research Council and Institute of Medicine 2015, pp. 78-81). The volume of NYS taxed cigarettes in 2012 was 52 percent lower than the sum of 2009 NYS taxed volume and 2009 untaxed shipments to NARS. Assuming 1-for-1 pass through of taxes to prices and accounting for the June 2010 tax hike and the fact that prior to June 2011 one-third of sales were non-taxed, between 2009 and 2012 the average price of cigarettes increased by 22 percent. The absolute value of the implied price-elasticity of demand between 2009 and 2012 is over 2, compared to consensus estimates that cigarette demand is inelastic and probably below 0.5 (DeCicca, Kenkel, and Lovenheim 2020).

${ }^{43}$ We extended our empirical model of premium use to include the consumer's distance to the nearest state with lower cigarette taxes, its interaction with the gap between that state's tax and the NYS tax, and the interactions with the regime change indicator and distance to a NAR. We do not find any evidence that the availability of lower-tax cigarettes from a border state blunted the impact of the regime change (see Appendix Table A11). In some post-regime change survey waves, the NYS-ATS directly asked about cross-state purchases. In 2014 and 2015, about five percent of smokers reported that they always purchase cigarettes from another state. Given the sample sizes (five percent corresponds to 28 or 29 respondents per year), the NYS-ATS does not provide much statistical power.
} 
were willing to pay at least an extra $\$ 4.35$ per pack rather than switch to an untaxed Indianmanufactured cigarette brand.

The high degree of consumer loyalty to national premium-brand cigarettes poses a puzzle that could be explored in future research. The national cigarette market has reached an equilibrium where the prices of all premium brands are about the same and are roughly $\$ 1.25$ per pack above the prices of non-premium brands. At the current price differential premium brands have about 70 percent market share. Our estimates suggest that as a group, the manufacturers of premium cigarettes could increase their prices relative to non-premiums and many consumers would remain loyal. That is, given the high degree of consumer brand loyalty we estimate, increasing the price of premium cigarettes might increase industry profits. However, our estimates do not shed light on what would happen if the manufacturer of one premium brand unilaterally increased its price. Premium brands like Marlboro and Camel have been in a decades-long competition for market share. Bulow and Klemperer (1998) develop a model where the prices of premium cigarettes are held down by price competition among premium brands for youth market share. A model along those lines might yield additional testable implications about the impact of the quasi-experiment we study.

Finally, we note that the impact of the tax regime change on the use of premium brand cigarettes was an unintended consequence. Because most estimates suggest that cigarette demand is inelastic but not perfectly so, policymakers can expect cigarette tax hikes to increase tax revenues and simultaneously reduce cigarette consumption. We find no evidence that the 2011 NYS tax regime change had either of these intended consequences. Another unresolved puzzle for future research is to reconcile the reduction in the total (off- plus on-reservation) 
volume of NYS cigarette sales, with the NYS-ATS data that do not show a corresponding reduction in self-reported smoking. Kurti et al. (2015) provide evidence that after the regime change, organized smuggling to supply the illegal New York City street market shifted from NARs to low-taxed states. The regime change might have also caused an increase in so-called casual smuggling, i.e., consumer purchases of cigarettes across state borders. Future research could fruitfully explore substitution between cigarettes from NARs and from low-taxed states by analyzing repeated cross-sectional data that includes multiple states with NAR markets and more variation in cross-border taxes. The travel restrictions and economic disruptions associated with the COVID-19 pandemic also might provide a novel source of variation to study cross-border cigarette purchases. 


\section{References}

Anderson, Soren T., Ryan Kellogg, Ashley Langer, and James M. Sallee (2013). “The

Intergenerational Transmission of Automobile Preferences: Empirical Evidence and Implications

for Firm Strategy." Journal of Industrial Economics, 63(4): 763-793.

Becker, Gary and Kevin Murphy (1993). "A Simple Theory of Advertising as a Good or a Bad."

Quarterly Journal of Economics 108 (4): 941-964.

Brandt, Allan M. (2007). The Cigarette Century: The Rise, Fall, and Deadly Persistence of the Product That Defined America. Basic Books: New York.

Bronnenberg, Bart J., Jean-Pierre Dubé, and Sridhar Moorthy, R. (2019). “The Economics of Brands and Branding." Working Paper.

Bronnenberg, Bart J., Jean-Pierre Dube, M. Gentzkow, and J. M. Shapiro (2015). “Do

Pharmacists Buy Bayer? Sophisticated Shoppers and the Brand Premium." Quarterly Journal of Economics 130.

Bulow, Jeremy and Paul Klemperer (1998). "The Tobacco Deal." Brookings Papers on Economic Activity: Microeconomics. Pp. 323-394.

Carpenter, Christopher S. and Michael T. Mathes (2016). “New Evidence on the Price Effects of Cigarette Tax Competition." Public Finance Review 44(3): 291-310 
Coin, Glenn (2011). “At Central New York's Indian Smoke Shops, the Marlboro Man Rides Away." Syracuse Post-Standard, July 17, 2011.

Cornelius, Monica E., Pete Driezen, Geoffrey Fong et al. (2015). "Trends in the use of Premium and Discount Cigarette Brands: Findings from the ITC (US) Surveys (2002-2011)", Tobacco Control 23: i48-i53.

Dawes, John (2014). “Cigarette brand loyalty and purchase patterns: An examination using US panel data", Journal of Business Research 67: 1933-1943.

DeCicca, Philip, Donald Kenkel, and Feng Liu (2015). “Reservation Prices: An Economic Analysis of Cigarette Purchases on Indian Reservations." National Tax Journal 68 (1): 93-118.

DeCicca, Philip, Donald Kenkel, and Michael Lovenheim (2020). "The Economics of Tobacco Control Regulations." National Bureau of Economic Research Working Paper 26923; Journal of Economic Literature forthcoming.

Deaton, Angus and John Muellbauer (1980). Economics and Consumer Behavior. Cambridge University Press: Cambridge.

DellaVigna, Stefano and Matthew Gentzkow (2019). “Uniform Pricing in U.S. Retail Chains.” Quarterly Journal of Economics 134 (4): 2011-2084.

Dube, Jean-Pierre, Gunter J. Hitsch, and Peter E. Rossi (2010). “State Dependence and Alternative Explanations for Consumer Inertia." RAND Journal of Economics 41(3): 417-445. 
Harding, Matthew, Ephraim Leibtag, and Michael Lovenheim (2012). "The Heterogeneous Geographic and Socioeconomic Incidence of Cigarette Taxes: Evidence from Nielsen Homescan Data." American Economic Journal: Economic Policy 4 (4): 169-98.

Heffetz, Ori (2011). "A Test of Conspicuous Consumption: Visibility and Income Elasticities." Review of Economics and Statistics 93 (4): 1101-1117.

Hortaçsu, Ali, Seyed Ali Madanizadeh, and Steven L. Puller (2017). "Consumer Inertia in the Residential Electricity Market." American Economic Journal: Economic Policy vol. 9, no. 4, pp. $192-226$.

Husband, R.W. and J. Godfrey (1934). "An experimental study of cigarette identification", Journal of Applied Psychology 18: 220-223.

Hyland, A., J.E. Bauer, Q. Li et al. (2005). “Higher cigarette prices influence cigarette purchase patterns", Tobacco Control 14: 86-92.

Jaffe, A. and A.G. Glaros (1986). "Taste dimensions in cigarette discrimination: A multidimensional scaling approach", Addictive Behaviors 11(4): 407-413.

Kurti, Marin, Klaus von Lampe, and Jacqueline Johnson (2015). "The Intended and Unintended Consequences of a Legal Measure to Cut the Flow of Illegal Cigarettes Into New York City: The Case of the South Bronx." American Journal of Public Health 105(4): 750-756.

Littman, R.A. and H.M. Manning (1954). "A methodological study of cigarette brand discrimination," Journal of Applied Psychology 38(3): 185-190. 
Nargis, Nigar, Geoffrey T. Fong, Frank J. Chaloupka, and Qiang Li. "The choice of discount brand cigarettes: a comparative analysis of International Tobacco Control surveys in Canada and the USA (2002-2005)." Tobacco control 23, no. suppl 1 (2014): i86-i96.

National Research Council and Institute of Medicine. (2015). Understanding the U.S. Illicit Tobacco Market: Characteristics, Policy Context, and Lessons from International Experiences. Committee on the Illicit Tobacco Market: Collection and Analysis of the International Experience, P. Reuter and M. Majmundar, Eds. Committee on Law and Justice, Division of Behavioral and Social Sciences and Education. Board on Population Health and Public Health Practice, Institute of Medicine. Washington, DC: The National Academies Press.

Prothro, T. (1953). "Identification of American, British and Lebanese cigarettes", Journal of Applied Psychology 37(1): 54-56.

Ramond, C.K., K. Rachal, and M.R. Marks (1950). “Brand discrimination among cigarette smokers", Journal of Applied Psychology 34(4): 282-284.

Saul, Stephanie (2008). "Suits Claim Wide Reach of Cigarettes From Tribes." New York Times, October 1, 2008.

Shum, Matthew (2004). “Does Advertising Overcome Brand Loyalty? Evidence from the Breakfast-Cereals Market." Journal of Economics and Management Strategy 13(2): 241-271. 
Siegel, M., Nelson, D. E., Peddicord, J. P., Merritt, R. K., Giovino, G. A., \& Eriksen, M. P. (1996). "The extent of cigarette brand and company switching: results from the Adult Use-of-Tobacco Survey." American Journal of Preventive Medicine, 12(1), 14-16.

Skaczkowski, G., S. Durkin, Y. Kashima and M. Wakefield (2018). “Influence of premium versus masked cigarette brand name on the experienced taste of a cigarette after tobacco plain packaging in Australia: An experimental study", forthcoming in BMC Public Health.

Sobel, Russell S., and Thomas A. Garrett, 1997. "Taxation and Product Quality: New Evidence from Generic Cigarettes." Journal of Political Economy 105 (4), 880-887.

Tucker, Clyde, Brian Kojetin, and Roderick Harrison, 1995. A Statistical Analysis of the CPS Supplement on Race and Ethnic Origin. Bureau of Labor Statistics, Washington, DC.

U.S. Department of Health and Human Services (2014). The Health Consequences of Smoking50 Years of Progress: A Report of the Surgeon General. Atlanta: U.S. Department of Health and Human Services, Centers for Disease Control and Prevention, National Center for Chronic Disease Prevention and Health Promotion, Office on Smoking and Health. 
Table 1: Sample characteristics for the NYS-ATS and NHP analysis samples.

\begin{tabular}{|c|c|c|c|}
\hline & NYS-ATS & NHP-Full & NHP-Panel \\
\hline Smoked Premium brands & 0.714 & 0.682 & 0.652 \\
\hline Smoked Native brands & 0.075 & 0.061 & $0.098^{\dagger}$ \\
\hline Distance (in 100s of miles) & 0.573 & 0.546 & 0.553 \\
\hline Cigarette tax (in cents per pack) & 250.4 & 275.7 & $320.4^{\dagger}$ \\
\hline Age 18-24 & 0.088 & 0.002 & $0.000^{\dagger}$ \\
\hline Age 25-34 & 0.164 & 0.059 & 0.040 \\
\hline Age 35-44 & 0.207 & 0.148 & 0.120 \\
\hline Age 45-54 & 0.253 & 0.335 & 0.330 \\
\hline Age 55-64 & 0.180 & 0.292 & $0.321^{\dagger}$ \\
\hline Age 65+ & 0.108 & 0.164 & $0.189^{\dagger}$ \\
\hline Female & 0.569 & $0.875^{*}$ & 0.842 \\
\hline Male & 0.431 & $0.710^{*}$ & $0.735^{\dagger}$ \\
\hline White & 0.717 & $0.810^{*}$ & $0.856^{\dagger}$ \\
\hline Black & 0.141 & $0.112^{*}$ & 0.097 \\
\hline Hispanic & 0.092 & ----" & ---- \\
\hline Other race reported & 0.050 & $0.077^{*}$ & 0.047 \\
\hline Less than HS & 0.116 & 0.040 & 0.028 \\
\hline High school & 0.358 & 0.320 & 0.314 \\
\hline Some college & 0.309 & 0.331 & 0.329 \\
\hline College or higher & 0.217 & 0.309 & 0.329 \\
\hline Income $<30 \mathrm{k}$ & 0.386 & 0.302 & 0.298 \\
\hline Income $30-59 k$ & 0.302 & 0.368 & 0.385 \\
\hline Income $60-89 \mathrm{k}$ & 0.117 & $0.232^{*}$ & 0.217 \\
\hline Income $90 \mathrm{k}^{+}$ & 0.097 & $0.098^{*}$ & 0.100 \\
\hline Income missing & 0.098 & ---- & ---- \\
\hline Region - Chautauqua-Alleghany & 0.031 & 0.036 & 0.036 \\
\hline Region - Niagara & 0.142 & 0.183 & 0.193 \\
\hline Region - Finger Lakes & 0.152 & 0.185 & 0.169 \\
\hline Region - Thousand Islands & 0.036 & 0.024 & 0.031 \\
\hline Region - Adirondacks & 0.048 & 0.026 & 0.034 \\
\hline Region - Cent. Leatherstocking & 0.068 & 0.047 & 0.056 \\
\hline Region - Saratoga-Capital & 0.059 & 0.052 & $0.063^{\dagger}$ \\
\hline Region - Catskills & 0.026 & 0.018 & 0.019 \\
\hline Region - Hudson Valley & 0.068 & 0.083 & 0.071 \\
\hline Region - New York City & 0.272 & 0.239 & 0.213 \\
\hline Region - Long Island & 0.098 & 0.106 & 0.114 \\
\hline Observations & 9,732 & 24,297 & 10,783 \\
\hline Number of households & ---- & 2,024 & 308 \\
\hline
\end{tabular}

Notes: NYS-ATS column corresponds to our 2003-2016 analysis sample, NHP-Full corresponds to our 2004-2016 analysis sample from those data, and NHP-Panel corresponds to our 2004-2016 panel sample from those data.

*The definitions of these variables in the NHP differ from the NYS-ATS definitions. In the NHP, households can report the presence of a female head of household, a male head of household, or the presence of both; as a result, the means for Female and Male do not sum to one. The NHP does not report information on whether the household heads are Hispanic. The NHP also reports slightly different income categories: in particular, the two top brackets are $\$ \$ 60 \mathrm{k}-99 \mathrm{k}$ and $\$ 100 \mathrm{k}$ or more.

${ }^{\dagger}$ Indicates difference between NHP-Full and NHP-Panel sample is statistically significant at the $5 \%$ level. 
Table 2: Reduced form estimates of the impact of the regime change on the fraction of NYS smokers who usually purchase premium-brand cigarettes.

\begin{tabular}{lccc}
\hline \hline & & & \\
Selected Regressors & NYS-ATS & NHP--Full & NHP--Panel \\
\hline Post $\left(\beta_{1}\right)$ & $-0.1841^{* * *}$ & $-0.1150^{* *}$ & $-0.1500^{* * *}$ \\
& $(0.0366)$ & $(0.0472)$ & $(0.0557)$ \\
Distance $\left(\beta_{2}\right)$ & & & \\
& $-0.0657^{*}$ & -0.0361 & -0.0374 \\
& $(0.0368)$ & $(0.0886)$ & $(0.1420)$ \\
Post* Distance $\left(\beta_{3}\right)$ & & & \\
& $0.2075^{* * *}$ & $0.2750 * * *$ & $0.2810^{* * *}$ \\
& $(0.0426)$ & $(0.0637)$ & $(0.0788)$ \\
Cigarette Tax & & & \\
& -0.0093 & 0.0054 & 0.0063 \\
Wave & $(0.0087)$ & $(0.0118)$ & $(0.0150)$ \\
& & & -0.0007 \\
$\mathrm{R}^{2}$ & 0.0010 & -0.0004 & $(0.0006)$ \\
Dependent Mean & $(0.0008)$ & $(0.0004)$ & 0.369 \\
Sample Size $(\mathrm{N})$ & 0.196 & 0.223 & 0.655 \\
Number of Households & 0.714 & 0.683 & 10,783 \\
\hline \hline
\end{tabular}

Notes: All models also contain flexible controls race, gender, education, income, as well as region fixed effects. Standard errors appear in parenthesis; they are clustered at the county level in the NYS-ATS data and at the zip code level in the NHP data. $* * * p<0.01, * * p<0.05, *$ $p<0.1$ 
Table 3: Reduced form estimates of the impact of the regime change on the fraction of NYS smokers who purchase Native-produced cigarette brands.

\begin{tabular}{lccc}
\hline \hline & & & \\
Selected Regressors & NYS-ATS & NHP--Full & NHP--Panel \\
\hline Post $\left(\beta_{1}\right)$ & $0.1962^{* * *}$ & $0.1270^{* * *}$ & $0.1190^{* * *}$ \\
& $(0.0458)$ & $(0.0353)$ & $(0.0432)$ \\
Distance $\left(\beta_{2}\right)$ & & & \\
& 0.0019 & -0.0039 & -0.0027 \\
& $(0.0275)$ & $(0.0351)$ & $(0.0609)$ \\
Post* Distance $\left(\beta_{3}\right)$ & & & \\
& $-0.2572 * * *$ & $-0.2280 * * *$ & $-0.2110^{* * *}$ \\
Cigarette Tax & $(0.0564)$ & $(0.0477)$ & $(0.0588)$ \\
& & & \\
Wave & 0.0003 & $-0.0202 * * *$ & $-0.0219 * * *$ \\
& $(0.0068)$ & $(0.0062)$ & $(0.0090)$ \\
\hline $\mathrm{R}^{2}$ & & & $0.0018^{* * *}$ \\
Dependent Mean & $0.0028 * * *$ & $0.0015^{* * *}$ & $(0.0004)$ \\
Sample Size $(\mathrm{N})$ & $(0.0007)$ & $(0.0003)$ & 0.360 \\
Number of Households & 0.188 & 0.199 & 10,783 \\
\hline \hline
\end{tabular}

Notes: All models also contain flexible controls race, gender, education, and income, as well as region fixed effects. Standard errors appear in parenthesis; they are clustered at the county level in the NYS-ATS data and at the zip code level in the NHP data. ${ }^{* * *} p<0.01,{ }^{* *} p<0.05,{ }^{*}$ $p<0.1$. 
Table 4A: Reduced form estimates of the impact of the regime change on the fraction of NYS smokers who usually purchase premium-brand cigarettes, by age group

\begin{tabular}{|c|c|c|c|c|}
\hline & \multicolumn{2}{|c|}{$18-44$ years old } & \multicolumn{2}{|c|}{45 years +} \\
\hline & NYS-ATS & NHP-Full & NYS-ATS & NHP-Full \\
\hline Post & $\begin{array}{c}-0.2259 * * * \\
(0.0398)\end{array}$ & $\begin{array}{c}-0.1965^{* *} \\
(0.0792)\end{array}$ & $\begin{array}{c}-0.1544 * * * \\
(0.0439)\end{array}$ & $\begin{array}{l}-0.0723 \\
(0.0497)\end{array}$ \\
\hline Distance & $\begin{array}{l}-0.0532 \\
(0.0452)\end{array}$ & $\begin{array}{c}-0.2207^{* *} \\
(0.1072)\end{array}$ & $\begin{array}{l}-0.0787 \\
(0.0498)\end{array}$ & $\begin{array}{c}0.0224 \\
(0.0921)\end{array}$ \\
\hline Post*Distance & $\begin{array}{c}0.2281 * * * \\
(0.0494)\end{array}$ & $\begin{array}{c}0.2029 * * \\
(0.1021)\end{array}$ & $\begin{array}{c}0.1962 * * * \\
(0.0529)\end{array}$ & $\begin{array}{c}0.2528 * * * \\
(0.0671)\end{array}$ \\
\hline $\mathrm{R}^{2}$ & 0.144 & 0.305 & 0.191 & 0.251 \\
\hline Dependent Mean & 0.8113 & 0.7820 & 0.6359 & 0.6605 \\
\hline Sample Size (N) & 4,462 & 4,532 & 5,270 & 19,765 \\
\hline Number of households & --- & 584 & --- & 1,537 \\
\hline
\end{tabular}

Notes: Standard errors appear in parenthesis; they are clustered at the county level in the NYSATS data and at the zip code level in the NHP data. ${ }^{* * *} p<0.01, * * p<0.05,{ }^{*} p<0.1$. All models contain the same covariates as the models that generated our main estimates as presented in Table 2. 
Table 4B: Reduced form estimates of the impact of the regime change on the fraction of NYS smokers who usually purchase premium-brand cigarettes, by education group

\begin{tabular}{|c|c|c|c|c|}
\hline & \multicolumn{2}{|c|}{ High school or less } & \multicolumn{2}{|c|}{ Some college or more } \\
\hline & NYS-ATS & NHP-Full & NYS-ATS & NHP-Full \\
\hline Post & $\begin{array}{c}-0.1411^{* * *} \\
(0.0399)\end{array}$ & $\begin{array}{l}-0.0573 \\
(0.0733)\end{array}$ & $\begin{array}{c}-0.2256 * * * \\
(0.0446)\end{array}$ & $\begin{array}{c}-0.1371 * * \\
(0.0564)\end{array}$ \\
\hline Distance & $\begin{array}{l}-0.0618 \\
(0.0452)\end{array}$ & $\begin{array}{l}-0.1485 \\
(0.1123)\end{array}$ & $\begin{array}{l}-0.0701 \\
(0.0513)\end{array}$ & $\begin{array}{l}-0.0584 \\
(0.1090)\end{array}$ \\
\hline Post*Distance & $\begin{array}{c}0.1761 * * * \\
(0.0516)\end{array}$ & $\begin{array}{c}0.1604 \\
(0.1054)\end{array}$ & $\begin{array}{c}0.2381 * * * \\
(0.0487)\end{array}$ & $\begin{array}{c}0.3023 * * * \\
(0.0708)\end{array}$ \\
\hline $\mathrm{R}^{2}$ & 0.233 & 0.315 & 0.155 & 0.243 \\
\hline Dependent Mean & 0.6768 & 0.6390 & 0.7520 & 0.7080 \\
\hline Sample Size (N) & 4,619 & 8,738 & 5,113 & 15,559 \\
\hline Number of households & --- & 757 & --- & 1,353 \\
\hline
\end{tabular}

Notes: Standard errors appear in parenthesis; they are clustered at the county level in the NYSATS data and at the zip code level in the NHP data. ${ }^{* * *} p<0.01, * * p<0.05,{ }^{*} p<0.1$. All models contain the same covariates as the models that generated our main estimates as presented in Table 2. 
Table 4C: Reduced form estimates of the impact of the regime change on the fraction of NYS smokers who usually purchase premium-brand cigarettes, by income group

\begin{tabular}{|c|c|c|c|c|}
\hline & \multicolumn{2}{|c|}{$\begin{array}{c}\text { Household income }< \\
\$ 30,000\end{array}$} & \multicolumn{2}{|c|}{$\begin{array}{l}\text { Household income } \\
\$ 30,000 \text { or more }\end{array}$} \\
\hline & NYS-ATS & NHP-Full & NYS-ATS & NHP-Full \\
\hline Post & $\begin{array}{c}-0.1404 * * * \\
(0.0278)\end{array}$ & $\begin{array}{l}-0.1051 \\
(0.0882)\end{array}$ & $\begin{array}{c}-0.2209 * * * \\
(0.0581)\end{array}$ & $\begin{array}{c}-0.1251^{* *} \\
(0.0541)\end{array}$ \\
\hline Distance & $\begin{array}{c}-0.0904^{*} \\
(0.0491)\end{array}$ & $\begin{array}{l}-0.1315 \\
(0.1160)\end{array}$ & $\begin{array}{c}-0.0461 \\
(0.0402)\end{array}$ & $\begin{array}{c}0.0405 \\
(0.1032)\end{array}$ \\
\hline Post*Distance & $\begin{array}{c}0.2098^{* * *} \\
(0.0369)\end{array}$ & $\begin{array}{c}0.3791 * * \\
(0.1287)\end{array}$ & $\begin{array}{c}0.2142 * * * \\
(0.0586)\end{array}$ & $\begin{array}{c}0.2242^{* * *} \\
(0.0693)\end{array}$ \\
\hline $\mathrm{R}^{2}$ & 0.242 & 0.301 & 0.162 & 0.227 \\
\hline Dependent Mean & 0.6603 & 0.6191 & 0.7516 & 0.7129 \\
\hline Sample Size (N) & 3,762 & 7,702 & 5,970 & 15,595 \\
\hline Number of households & --- & 673 & --- & 1,506 \\
\hline
\end{tabular}

Notes: Standard errors appear in parenthesis; they are clustered at the county level in the NYSATS data and at the zip code level in the NHP data. ${ }^{* * *} p<0.01,{ }^{* *} p<0.05,{ }^{*} p<0.1$. All models contain the same covariates as the models that generated our main estimates as presented in Table 2. 
Table 5: Pre-post estimates of the impact of the regime change by quintile of the predicted probability of always purchasing cigarettes on a NAR (i.e., $\rho$ in Equation 9).

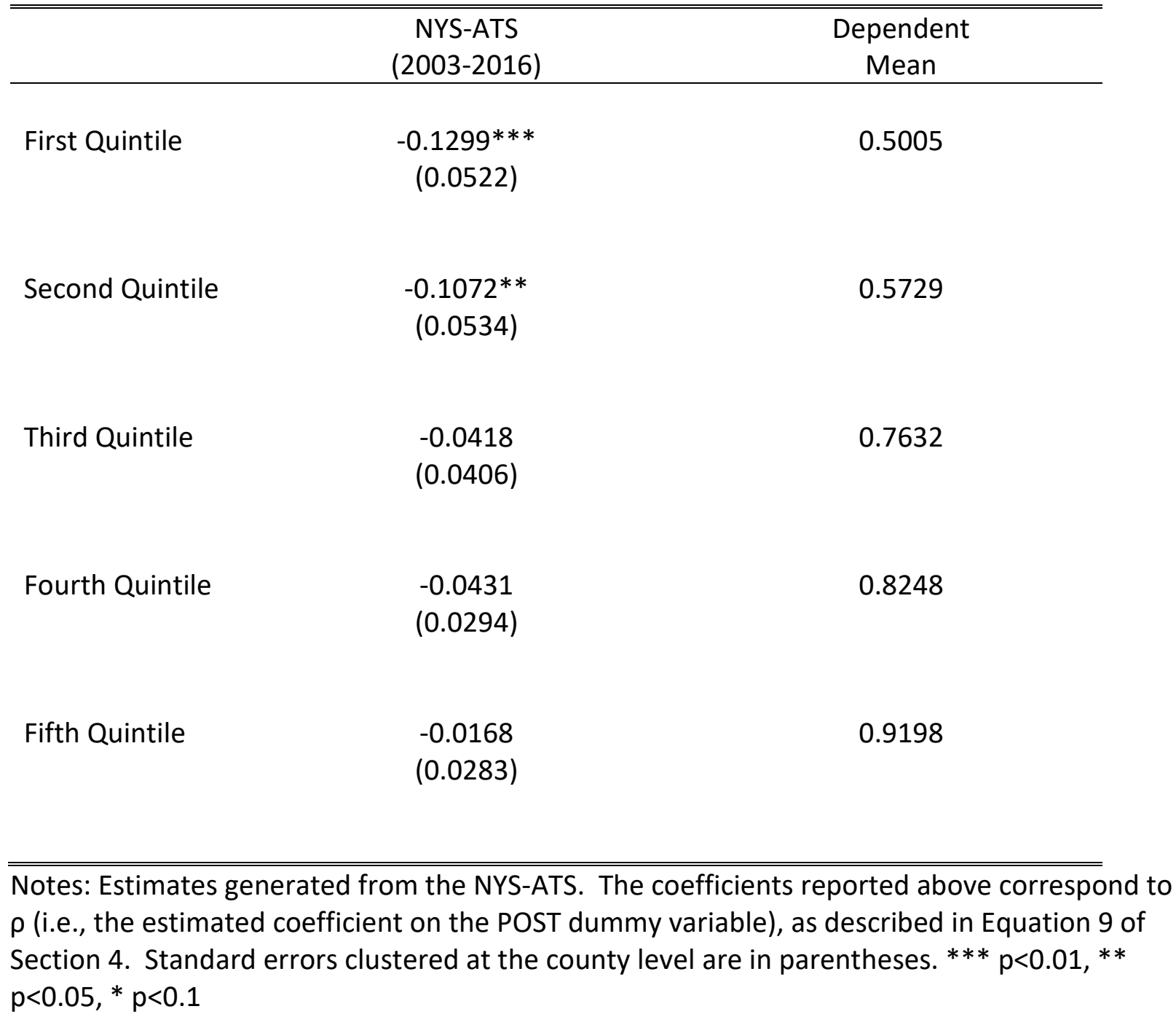


Table 6A: Placebo regression estimates of the impact of the regime change on the fraction of NYS smokers who usually purchase premium-brand cigarettes-NYS-ATS

\begin{tabular}{|c|c|c|c|c|c|}
\hline & \multicolumn{5}{|c|}{ Regime change artificially imposed as of: } \\
\hline & June 2004 & June 2005 & June 2006 & June 2007 & June 2010 \\
\hline \multicolumn{6}{|c|}{ Selected Regressors } \\
\hline Post & $\begin{array}{c}0.0206 \\
(0.0390)\end{array}$ & $\begin{array}{l}-0.0085 \\
(0.0205)\end{array}$ & $\begin{array}{l}-0.0150 \\
(0.0319)\end{array}$ & $\begin{array}{l}0.0123 \\
(0.454)\end{array}$ & $\begin{array}{l}-0.0626 \\
(0.0409)\end{array}$ \\
\hline Distance & $\begin{array}{c}-0.0767^{*} \\
(0.0421)\end{array}$ & $\begin{array}{c}-0.0580 * \\
(0.0307)\end{array}$ & $\begin{array}{c}-0.0668 * * \\
(0.0295)\end{array}$ & $\begin{array}{c}-0.0637^{* *} \\
(0.0286)\end{array}$ & $\begin{array}{c}-0.0665^{* *} \\
(0.0283)\end{array}$ \\
\hline Post*Distance & $\begin{array}{c}0.0346 \\
(0.0323)\end{array}$ & $\begin{array}{c}0.0071 \\
(0.0242)\end{array}$ & $\begin{array}{l}-0.0455 \\
(0.0300)\end{array}$ & $\begin{array}{l}-0.0293 \\
(0.0366)\end{array}$ & $\begin{array}{c}0.0480 \\
(0.0583)\end{array}$ \\
\hline $\mathrm{R}^{2}$ & 0.1734 & 0.1725 & 0.1729 & 0.1726 & 0.1726 \\
\hline Sample Size $(\mathrm{N})$ & 6,989 & 6,989 & 6,989 & 6,989 & 6,989 \\
\hline \multicolumn{6}{|c|}{$\begin{array}{l}\text { Notes: The models used to generate the estimates above use only observations gathered prior } \\
\text { to the regime change in June } 2011, \text { which accounts for the smaller sample size }(N=6,989) \text {, } \\
\text { relative to our main estimates in Table } 2 \text {. Standard errors clustered at the county level are in } \\
\text { parentheses } * * * p<0.01, * * p<0.05, * p<0.1 \text {. All placebo models contain the same covariates as } \\
\text { the models that generated our main estimates as presented in Table } 2 \text {. }\end{array}$} \\
\hline
\end{tabular}


Table 6B: Placebo regression estimates of the impact of the regime change on the fraction of NYS smoking households which usually purchase premium-brand cigarettes-NHP-Full.

\begin{tabular}{|c|c|c|c|c|c|}
\hline & \multicolumn{5}{|c|}{ Regime change artificially imposed as of: } \\
\hline & June 2006 & June 2007 & June 2008 & June 2009 & June 2010 \\
\hline \multicolumn{6}{|c|}{ Selected Regressors } \\
\hline Post & $\begin{array}{l}-0.0338 \\
(0.0423)\end{array}$ & $\begin{array}{l}-0.0526 \\
(0.0397)\end{array}$ & $\begin{array}{l}-0.0376 \\
(0.0417)\end{array}$ & $\begin{array}{l}0.0670 \\
(0.404)\end{array}$ & $\begin{array}{c}0.1300 * * * \\
(0.0540)\end{array}$ \\
\hline Distance & $\begin{array}{l}-0.0761 \\
(0.1060)\end{array}$ & $\begin{array}{l}-0.0607 \\
(0.0982)\end{array}$ & $\begin{array}{l}-0.0493 \\
(0.0929)\end{array}$ & $\begin{array}{l}-0.0407 \\
(0.0917)\end{array}$ & $\begin{array}{l}-0.0462 \\
(0.0918)\end{array}$ \\
\hline Post*Distance & $\begin{array}{c}0.0271 \\
(0.0707)\end{array}$ & $\begin{array}{c}0.0093 \\
(0.0582)\end{array}$ & $\begin{array}{l}-0.0123 \\
(0.0584)\end{array}$ & $\begin{array}{l}-0.0679 \\
(0.0641)\end{array}$ & $\begin{array}{l}-0.0963 \\
(0.0798)\end{array}$ \\
\hline $\mathrm{R}^{2}$ & 0.223 & 0.224 & 0.224 & 0.224 & 0.224 \\
\hline Sample Size (N) & 17,244 & 17,244 & 17,244 & 17,244 & 17,244 \\
\hline \multicolumn{6}{|c|}{$\begin{array}{l}\text { Notes: The models used to generate the estimates above use only observations gathered prior } \\
\text { to the regime change in June } 2011 \text {, which accounts for the smaller sample size }(N=17,244 \text { which } \\
\text { is generated by } 1,565 \text { households), relative to our main NHP-Full estimates in Table } 2 \text {. Standard } \\
\text { errors clustered at the zip code level are in parentheses. } * * * p<0.01, * * p<0.05, * p<0.1 \text {. All } \\
\text { placebo models contain the same covariates as the models that generated our main estimates } \\
\text { as presented in Table } 2 \text {. }\end{array}$} \\
\hline
\end{tabular}


Table 7: Reduced form estimates of the impact of the regime change on NYS smokers' behaviors -NYT-ATS.

\begin{tabular}{lcccc}
\hline & $\begin{array}{c}\text { Cigarettes } \\
\text { per day }\end{array}$ & $\begin{array}{c}\text { Past-year } \\
\text { quit }\end{array}$ & $\begin{array}{c}\text { Past-year } \\
\text { quit } \\
\text { attempt }\end{array}$ & $\begin{array}{c}\text { Intend to } \\
\text { quit }\end{array}$ \\
\hline Selected Regressors & & & & \\
\hline Post & $\begin{array}{c}1.4211^{* * *} \\
(0.4087)\end{array}$ & $\begin{array}{c}-0.0043 \\
(0.0119)\end{array}$ & $\begin{array}{c}0.0060 \\
(0.0188)\end{array}$ & $\begin{array}{c}0.0411^{*} \\
(0.0225)\end{array}$ \\
& & & & \\
& & & & \\
Distance & 0.5357 & $-0.0332^{*}$ & -0.0059 & 0.0019 \\
& $(0.7578)$ & $(0.0173)$ & $(0.0249)$ & $(0.0213)$ \\
& & & & \\
Post*Distance & & & & \\
& 0.1289 & $-0.0302^{* *}$ & $-0.0546^{* *}$ & $-0.0867^{* * *}$ \\
& $(0.4846)$ & $(0.0129)$ & $(0.0253)$ & $(0.0301)$ \\
& & & & \\
\hline $\mathrm{R}^{2}$ & & & & \\
\hline Dependent Mean & 13.0546 & 0.1448 & 0.5431 & 0.6379 \\
Sample Size (N) & 12,636 & 14,769 & 12,596 & 10,707 \\
\hline \hline
\end{tabular}

Notes: Standard errors clustered at the county level are in parentheses. ${ }^{* * *} p<0.01, * * p<0.05$, $* p<0.1$. All models contain the same covariates as the models that generated our main estimates as presented in Table 2 . The sample size varies across models because the questions that were asked varied across survey waves. 
Figure 1. Cigarette advertisement for Seneca brand cigarettes

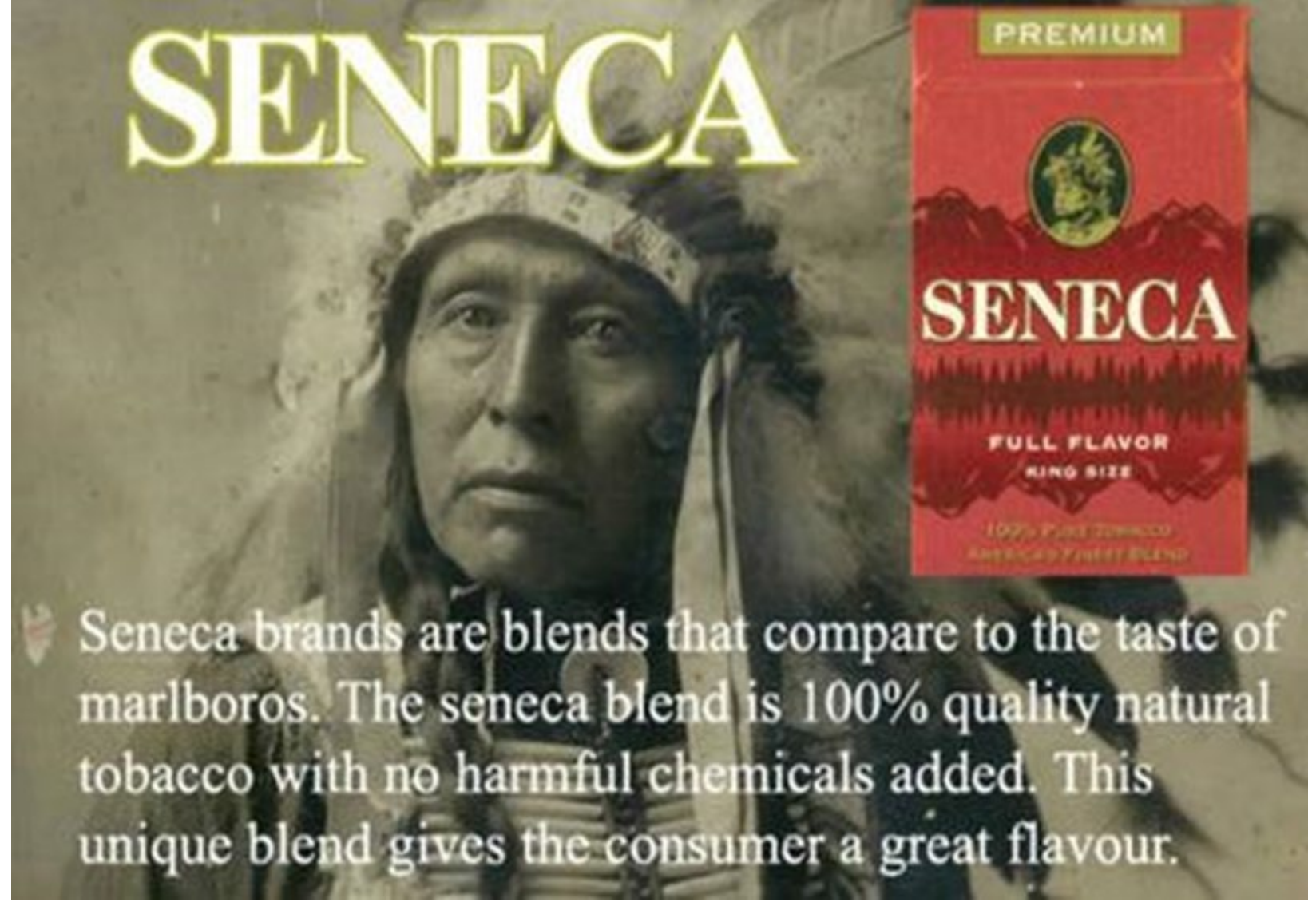


Figure 2: New York State Cigarette Excise Tax Collections, 1987 - 2016

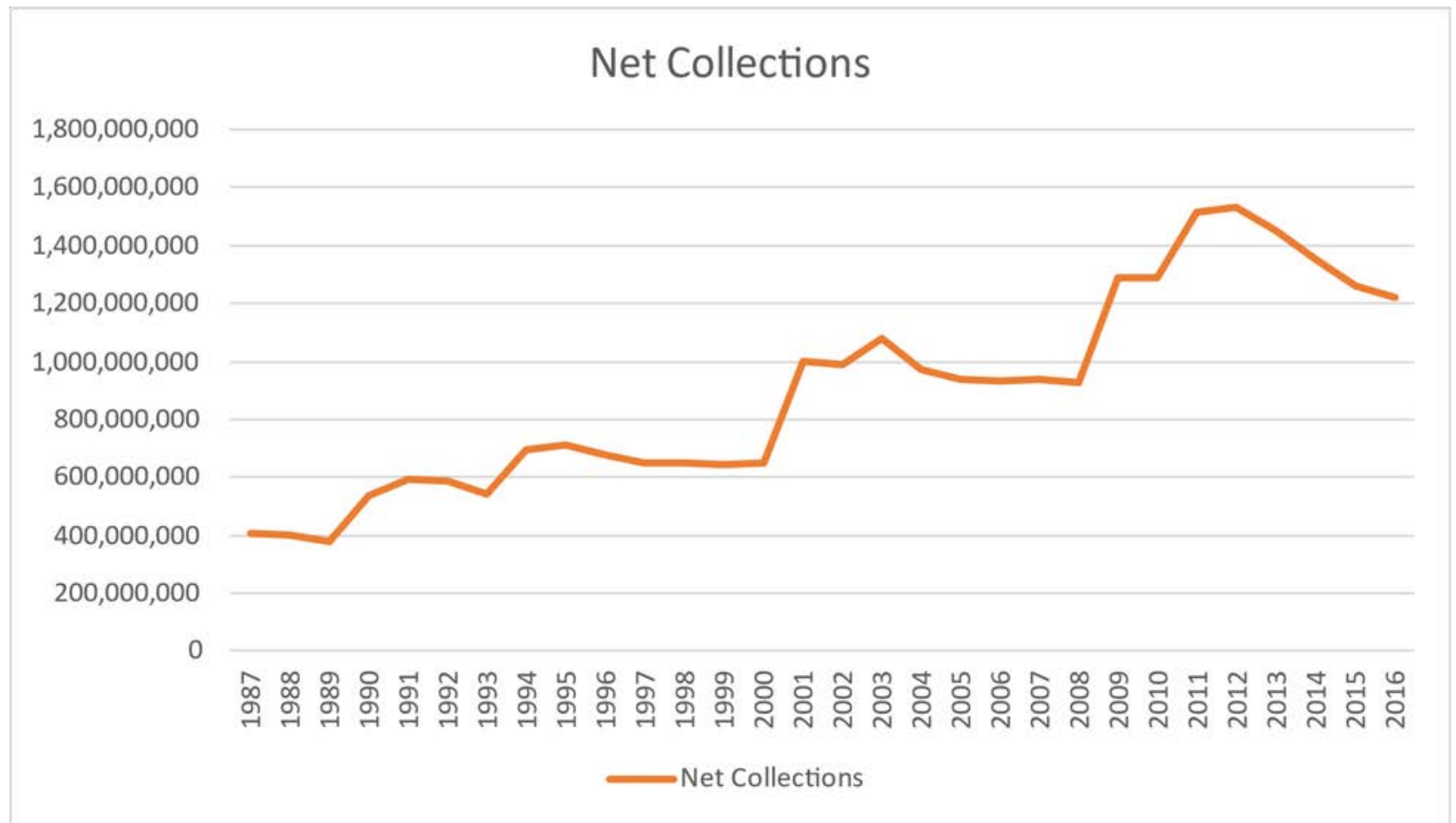

Source: New York State Department of Taxation and Finance. https://www.tax.ny.gov/pdf/201516 Collections/Table13.pdf 